\title{
Francia \\ y la guerra civil española: Los límites de una política
}

\author{
JUAN AVILÉs FARRÉ
}

A primeros de septiembre de 1936, un campesino extremeño planteó a unos perodistas extranjeros las siguientes preguntas: quién era el presidente de la República francesa y si era un buen republicano. El agudo observador que recogió la anécdota quedó impresionado de que, en una aldea remota, campesinos que quizá antes sólo tuvieran una vaga idea de la existencia de Francia hubieran Ilegado a la conclusión de que para ellos la actitud francesa era cuestión de vida o muerte ${ }^{1}$. De hecho lo era: en una guerra en la que los suministros bélicos exteriores eran imprescindibles y en la que la República perdió pronto el control del mar, la de Francia era la única frontera con un país amigo y su cierre suponía un estrangulamiento. A su vez la guerra española tuvo una gran relevancia para la política francesa. Antes de que se iniciara el conflicto el embajador en Madrid, Jean Herbette, explicaba en un despacho que la importancia de las relaciones franco-españolas era superior a la que cabría deducir del limitado poderío material de España, por dos motivos. Por su situación geográfica, sobre todo en caso de que un conflicto europeo obligara a Francia a transportar al teritorio metropolitano tropas de África del norte. Y por la analogía de los respectivos gobiernos: las dificultades en que se viera uno de ellos podían perjudicar al otro ${ }^{2}$. Había pues una cuestión estratégica y una cuestión política. Ambas obligaron a los dirigentes franceses a prestar una considerable atención al conflicto español, pero ambas también limitaron notablemente su margen de maniobra.

\footnotetext{
1 Borkenau, F., El reñidero español. París, Ruedo Ibérico, 1971, pág. 113.

${ }^{2}$ Ministère des Affaires étrangères, Paris (en adelante MAE Paris), Z Esp 213, Herbette, 4-6-1936.
} 


\section{LOS PROBLEMAS DE SEGURIDAD DE FRANCIA}

El peligro que la guerra española representó para Francia venía de que la instalación de un gobierno aliado con Alemania e Italia habria supuesto que Francia quedara cercada por potencias hostiles, un peligro que en los siglos XVI y XVII se había dado por la presencia de los Habsburgo en los tronos de Alemania y España y que en 1870, por la oferta de la corona española a un Hohenzollern, había sido el desencadenante de la guerra franco-prusiana. El hecho de que para un conflicto en gran escala Francia hubiera de recurrir a sus tropas de África del norte acentuaba el problema, ya que una base hostil en las Baleares haria muy insegura la ruta Argel-Marsella y obligaria a recurrir a la que desde Rabat a Burdeos y Brest bordeaba la costa occidental española, triplicando así el tiempo necesario para que las fronteras europeas de Francia quedaran completamente guarnecidas ${ }^{3}$. Además Francia dependía tanto del África del norte como de la misma España para importantes suministros de minerales y alimentos. En especial España era el primer productor mundial de piritas, principal materia prima para la obtención del ácido sulfúrico, que era un componente básico en varios sectores de la industria química, incluida la fabricación de explosivos ${ }^{4}$.

Tales consideraciones empujaban hacia una política activa respecto a la guerra española, que evitara el triunfo del bando apoyado por Italia y Alemania. Sin embargo toda la cuestión española no era, desde el punto de vista estratégico, más que un elemento subordinado al problema fundamental que constituía la amenaza alemana, acentuada desde que en 1933 se había establecido el régimen abiertamente revanchista de Hitler. Tras la I Guerra Mundial los Estados Unidos volvieron a su tradicional aislamiento y Gran Bretaña centró de nuevo sus energías en su imperio colonial, se propuso evitar nuevos compromisos en Europa y manifestó pronto una tendencia a aceptar que Alemania volviera a jugar un papel en el equilibrio europeo proporcionado a su poderío demográfico y económico. Ello dejó a los gobiernos de Paris en la poco envidiable situación de ejercer un papel de mantenedores del status quo surgido de la paz de Paris, que claramente estaba por encima de sus recursos humanos, económicos y por ende militares. Habia de hacer frente a una posible revan-

\footnotetext{
${ }^{3}$ Royal Institute of International Affairs, Political and Strategic Interests of the United Kingdom. Londres, Oxford University Press, 1939, pág. 58.

4 Borras Llop, J. M., «intereses económicos y actitudes politicas en las relaciones franco-españolas (1936-1939): el comercio de piritas", en AA.VV. Españoles y franceses en la primera mitad del siglo xx. Madrid, CSIC, 1986, págs. 65-70.
} 
cha alemana sin poder contar con la alianza rusa que antes de 1914 había servido de contrapeso frente a la poderosa Alemania. A cambio, Francia habia logrado una alianza con Checoslovaquia y Polonia, pero ello, a la vez que una garantía contra un ataque alemán contra ella, era también un peligro de verse arrastrada a una guerra no querida si Alemania atacaba a uno de estos dos países ${ }^{5}$.

El balance de la Primera guerra mundial habia sido dramático para los franceses, que habian tenido 1.300 .000 muertos y desaparecidos, el equivalente a la décima parte de su población activa masculina en 1913, a los que había que sumar 1.100 .000 hombres cuyas heridas de guerra les habian dejado secuelas permanentes ${ }^{6}$. Alemania habia sufrido unas pérdidas humanas proporcionalemente casi idénticas, habia tenido que ceder algunas regiones fronterizas y su capacidad militar habia quedado limitada por el tratado de Versalles, pero había conservado su unidad política y su poderío económico, muy superior al de Francia. A la altura de 1937 la producción industrial alemana equivalia al 11 por 100 del total mundial, un porcentaje que era muy inferior al norteamericano e incluso al soviético y sólo levemente superior al británico, pero que más que doblaba el francés?.

A los británicos, con la sensación de seguridad que les daban su insularidad y su poderosa marina de guerra, el peligro de una revancha alemana parecía remoto y no es extraño que fuera en el Reino Unido donde más popularidaci tuvo la Sociedad de Naciones como medio para la resolución pacífica de los problemas. A los franceses, en cambio, ni el desarme que se había impuesto a Alemania en Versalles ni las dudosas garantías de la Sociedad de Naciones bastaban para tranquilizarlos. El tratado de Locarno de 1925 habia sido una respuesta parcial a su inquietud, ya que Gran Bretaña e Italia se habian comprometido a garantizar las fronteras belgas y las francesas, aunque ni la una ni la otra garantizaron las fronteras de los aliados orientales de Francia, Polonia y Checoslovaquia. A cambio habia habido que reconocer a Mussolini un papel clave en el equilibrio europeo, a pesar de que su ideología fascista estaba

Sobre la política exterior y de defensa francesa en estos años, véase: DuRoselle, J. B., La décadence. Paris, Imprimerie nationale, 1979; AdAMTHWAITE, Anthony, France and the Coming of the Second World War, 1936-1939. Londres, F. Cass, 1977; DrEIFORT, J. E., Yvon De/bos at the Quai d'Orsay. Lawrence, University Press of Kansas, 1973; FrankEnsteIN, R., Le prix du réarmement français (1935-1939). París, Publications de la Sorbonne, 1982; Young, R. J., In Command of France: French Foreign Policy and Military Planning, 1933-1940. Cambridge Mass., Harvard University Press, 1978.

${ }^{6}$ Bernard, Ph., La fin d'un monde, 1914-1929. París, Seuil, 1975, págs. 108-112. 412.

${ }^{7}$ Kennedy, P., Auge y caida de las grandes potencias. Barcelona, Plaza Janés, 1989, pág. 
en neta contraposición con los principios democráticos de la Sociedad de Naciones.

La contradicción entre la política de poder que representaba Locarno y la política de ideales que representaba la Sociedad de Naciones, se puso en evidencia cuando en octubre de 1935 Mussolini se lanzó a la conquista de Abisinia. Ante ello las opciones que, de acuerdo con los conceptos tradicionales de la política exterior, se ofrecían a las potencias occidentales eran consentir la conquista, quizá mediante una conferencia internacional que concediera a Italia sólo una parte de lo que aspiraba, o recurrir a la amenaza militar. Desde un punto de vista pragmático probablemente fuera preferible la primera opción, ya que la amistad de Mussolini era en aquel momento especialmente valiosa. Había sido en efecto la Italia fascista, al desplegar sus divisiones en la frontera austriaca, la que en julio de 1934 habia impedido a Hitler apoyar al frustrado golpe de Estado nazi que tuvo lugar en Viena, y en abril de 1935 una conferencia en la localidad italiana de Stresa había sugerido la posibilidad de un frente común entre Gran Bretaña, Francia e Italia en defensa del statu quo. Ocurria sin embargo que las dos soluciones al problema abisinio que las potencias occidentales habrian podido adoptar guiadas por la política de poder eran inmorales desde el punto de vista de los ideales de paz y respeto internacionales. No se podia consentir la invasión de un miembro de la Sociedad de Naciones ni tampoco incurrir en el peligro de una guerra. Se recurrió a las sanciones económicas, que no impidieron que Italia concluyera la conquista de Abisinia en mayo de 1936, pero acabaron con el entendimiento de Stresa.

Si la baza italiana no dio mucho juego a Francia, tampoco lo dio la baza rusa. Dado el interés estratégico de la alianza, la diferencia de regimenes no tenía por qué impedir a la República francesa un acuerdo con la Rusia soviética, como no se lo había impedido con la Rusia de los zares. De hecho fue un gobierno francés de derechas, el de Pierre Laval, el que firmó un pacto franco-soviético en mayo de 1935, pero este pacto nunca llegó a concretarse en acuerdos militares ${ }^{8}$. En realidad la Rusia soviética si que era una aliada más problemática que la de los zares, que nunca había pretendido imponer su sistema político a otras naciones ni habia contado para ello con la colaboración de partidos afines en Francia y otros países.

\footnotetext{
${ }^{8}$ Duroselle, J. B., La Décadence, págs. 139-142. Haslam, J., The Soviet Union and the Struggle for Collective Security. Nueva York, St. Martin's, 1984, págs. 27-51 y 80-106. HocHMAN, J., The Soviet Union and the Failure of Collective Security. Ithaca, Cornell University Press, 1984, págs. 37-55.
} 
Francia y la guerra civil española: ...

Así es que Francia no contaba con sólidas alianzas cuando en marzo de 1936, dos meses antes de la formación del gobierno Blum, Alemania remilitarizó, en violación del tratado de Versalles, la zona renana. Aunque el poderío militar alemán no era todavía muy grande, los jefes militares franceses lo sobreestimaron. Además la opinión pública francesa, no digamos la británica, no aceptaba arriesgar una guerra para evitar que los alemanes remilitarizaran una parte de su propio territorio. El gobierno no tomó pues medidas para evitarlo. A cambio obtuvo una pequeña compensación, ya que el gobierno británico se avino a una vieja aspiración francesa: la apertura de conversaciones entre los respectivos estados mayores. Lo que en ellas ofrecieron los británicos no fue desde luego muy alentador: en caso de conflicto estarían en condiciones de enviar en un plazo de dos semanas dos divisiones al continente ${ }^{9}$. Con todo, ante la amenaza de Alemania, el deterioro de las relaciones con Italia y las dificultades para hacer efectivo el entendimiento con la Unión Soviética, era crucial para Francia la colaboración con Gran Bretaña. Ello hizo que, respecto a la cuestión española, los sucesivos gobiernos franceses del Frente Popular se esforzaran en que sus posiciones no se alejaran de las del gobierno conservador británico.

\section{EL PANORAMA POLITIICO FRANCÉS}

Tres elementos del ambiente político francés tuvieron una incidencia en la politica adoptada en 1936 respecto al conflicto español: la presencia de gobiernos análogos en ambos países, el agudo enfrentamiento de las fuerzas políticas conforme a líneas de fractura también análogas a las que existian en España y la amplia difusión del pacifismo.

La coalición electoral que triunfó en las elecciones francesas de abril y mayo de 1936, integrada por los partidos radical, comunista y socialista, era casi idéntica a la que había triunfado en las elecciones españolas de febrero de aquel año, cuyos principales componentes eran los partidos de Izquierda Republicana, socialista y comunista. Existían sin embargo diferencias importantes. La Izquierda Republicana representaba una izquierda liberal de clase media no muy distinta de la encarnada por el partido radical francés, pero dentro de este el tono era más conservador, en parte porque los objetivos fundamentales de su programa, como asentar el ré-

${ }^{9}$ Duroselle, J. B., La Décadence, págs. 153-179. Bond, B., British Military Policy between the Two World Wars. Oxford, Clarendon Press, 1980, págs. 225-228. 
gimen republicano o disminuir la influencia de la Iglesia en la vida pública, se habian logrado hacia décadas. El partido comunista francés era mucho más poderoso que el español, aunque siendo ambos secciones de un mismo movimiento internacional, ello no conducia a diferencias sustanciales en su línea política. Mucho más importante era que los socialistas franceses fueran el eje del gobierno frentepopulista de su pais, cuya jefatura asumieron en la persona de Leon Blum; mientras que los españoles no solamente quedaron fuera del gobierno, ejercido en exclusiva por los republicanos de izquierda, sino que un importante sector de ellos, encabezado por Largo Caballero, no ocultaba que la experiencia del Frente Popular no era para ellos sino una breve etapa en el camino hacia la dictadura del proletariado. A ello se sumaba que la crispación sociopolítica era mucho más aguda en España que en Francia. La formidable oleada huelguística que agitó a Francia en junio de 1936 no desmiente esta afirmación, ya que aquella fue en conjunto ordenada, en contraste con las violencias que acompañaban en ese momento a las huelgas españolas. En definitiva, mientras que las fuerzas politicas y sindicales integradas en el Frente Popular francés se esforzaban en canalizar las reivindicaciones obreras, en España no sólo la CNT, sino la UGT, controlada por los caballeristas, trataban de impulsarlas en un sentido revolucionario ${ }^{10}$.

El embajador Herbette era consciente de los peligros de la situación española. El 17 de abril informaba que ésta parecía encaminarse hacia un choque entre los militares de derechas y las masas populares de la extrema izquierda, sin que el Gobierno tuviera la previsión ni la autoridad necesarias para dominar el conflicto. A pesar de ello consideraba perjudiciales las críticas que la prensa francesa publicaba al respecto porque, según explicaba el 1 de mayo, los partidos de izquierda a los que tales críticas irritaban eran los únicos que sostenian en España la causa de Francia. Es más, el 14 de mayo, tras la formación del gobierno Casares Quiroga, Herbette informaba que no era probable que en el mundo político español se pudiera encontrar un equipo gubernamental mejor dispuesto hacia Francia ${ }^{11}$.

${ }^{10}$ El mejor estudio del Frente Popular francés es el de: JACKson, J., The Popular Front in France. Cambridge, University Press, 1988. Véase también: Lefranc, Georges, Histoire du Front Populaire. París, Payot 1974; y LEVY, D. A. L., "The French Popular Front, 1936-1937", en Graham, H. and Preston, P. (eds.), The Popular Front in Europe. Basingstoke, MacMillan, 1987, págs. 58-83. Para una comparación entre ambos casos: AleXander, M. S. y GraHam, H. (eds.), The French and Spanish Popular Fronts. Cambridge, University Press, 1989.

1 Citado en Paez-Camino, F., La significación de Francia en el contexto internacional de la Segunda República española, tesis doctoral. Madrid, Universidad Complutense, 1989, págs. 1.095 y 1.120 . 
Las críticas al Frente Popular español a las que Herbette aludía fueron frecuentes en los periódicos de derecha con motivo de la campaña electoral francesa, en la que el ejemplo español fue utilizado como prueba de los males que se derivarian de una victoria frentepopulista en la misma Francia. De esta manera los acontecimientos españoles, incluso antes del inicio de la guerra, contribuyeron a agudizar la ya profunda división de la opinión pública francesa. El habitualmente moderado Le Temps, al que se tenía por cercano a los puntos de vista del Quai d'Orsay, llegó a escribir el 19 de abril que los propósitos revolucionarios eran los mismos en ambos países, pero que en Francia se estaba en la primera fase de las operaciones y en España en la segunda: «primero la papeleta de voto, después la antorcha y el revólver» ${ }^{12}$. El estallido revolucionario que siguó al 18 de julio, en las áreas en la que el levantamiento militar fracasó, exacerbaría al extremo esta actitud, con lo que cualquier ayuda del Gobierno Blum a la República española habría ido directamente en contra de los más profundos sentimientos de un sector importante de la opinión francesa, en un momento en que un consenso nacional era importante debido a las amenazas exteriores.

Junto a esa división de la opinión, el sentimiento pacifista, particularmente agudo en la izquierda, era otro de los factores por los que el gobierno francés difícilmente podía emprender una política de la que se pudiera temer que condujera a una guerra con Alemania o Italia. Las monstruosas pérdidas humanas causadas por la primera guerra mundial habian impulsado la corriente pacifista, que se hacía notar tanto entre los militantes sindicales, sobre todo en el poderoso sindicato de maestros que en su congreso de agosto de 1936 se pronunció por el desarme unilateral, como en la masa de la población, muy especialmente entre los campesinos. De los partidos políticos aquel en que más se hacia sentir el pacifismo era precisamente el socialista, en el que su principal representante era Paul Faure. Por último existía un pequeño sector de la opinión que estaba a favor del pacifismo integral, es decir que consideraba preferible la ocupación extranjera a la guerra, como argumentó el pensador socialista Félicien Challaye en un libro de 1933 significativamente titulado Pour la paix désarmée, même en face d'Hitler. En cuanto al propio Blum, habia seguido fiel hasta 1934 a la vieja tradición socialista de votar en contra de los presupuestos militares y en 1935 había votado en contra de la ampliación del servicio militar de uno a dos años, aunque poste-

12 Breen, C., La droite française et la guerre d'Espagne. Ginebra, Medécine et Hygiene, 1973, págs. 25-26. Borras Llop, J. M., Francia ante la guerra civil española. Madrid, CIS, 1981, págs. 101-110. 
riormente iría evolucionando hacia una posición de mayor firmeza en política exterior que le alejaría del pacifismo de Faure. La sangría causada por la guerra mundial habia empujado también hacia el pacifismo a la derecha, de manera que la opinión francesa fue unánime durante la crisis renana de marzo de 1936: lo principal era evitar la guerra ${ }^{13}$.

\section{LOS ORIGENES DE LA NO INTERVENCIÓN}

A lo largo de toda la contienda, la política francesa hacia España en lo esencial se atuvo a la línea adoptada en las primeras semanas. El período crucial se sitúa entre al 20 de julio de 1936, fecha en que el jefe del gobierno francés, el socialista León Blum, recibió una petición de envío de armas por parte de su homólogo español José Giral y el 9 de septiembre, fecha en la que se constituyó en Londres el Comité de no intervención. Pero el final del período de indecisión puede incluso ser adelantado para situarlo el dia 8 de agosto en que el gobierno francés reafirmó su acuerdo de no enviar armas a España.

Las armas solicitadas por Giral el 20 de julio no eran muchas, pero podían jugar un papel importante en esos momentos iniciales de la contienda, en que ambos bandos estaban muy insuficientemente equipados. Destacaba sobre todo la petición de 20 bombarderos Potez con sus correspondientes pilotos. La reacción de Blum fue inicialmente favorable. Al parecer pensó que una pequeña ayuda, que se podía mantener secreta, bastaría para que el gobierno español aplastara rápidamente lo que él tomaba por un simple pronunciamiento. Para organizarla recurrió a los tres ministros implicados, Delbos, de Asuntos exteriores, Daladier, de Defensa y Cot, del Aire, los tres radicales. Pero antes de que todo estuviera listo, Blum y Delbos hubieron de partir para Londres, donde el 23 de julio tenian concertada una importante reunión con los ministros británicos y belgas para preparar un nuevo acuerdo que reemplazara al tratado de Locarno. En ella no se trató de la cuestión española, pero al despedir a Leon Blum, según contaría éste años después, el secretario del Foreign

${ }^{13}$ Dreyfus, M., "Pacifistes socialistes et humanistes dans les années trente», Revue d'histoire moderne et contemporaine, XXXV (1988), págs. 452-469. VILLEPIN, P., "Plutôt la servitude que la guerre!: la pacifisme integral dans les années trente", Relations internationales, 53 (1988), págs. 53-77. Sobre Blum, el mejor estudio es el de CoLton, J., Leon Blum. Paris, Fayard, 1968. 
Office Anthony Eden le preguntó si iban a enviar armas a España y le recomendó prudencia ${ }^{14}$.

De regreso a París, el 24 de julio, Blum se encontró con una situación extremadamente tensa. El periodista y político Henri de Kerillis, al que habian informado miembros de la Embajada española simpatizantes con los rebeldes, habia revelado la proyectada ayuda en L'Echo de Paris y existía una fuerte emoción en medios parlamentarios. Tanto el presidente de la República, Albert Lebrun, como los del Senado, Jules Jeanneney, y la Cámara de diputados, Edouard Herriot, desaconsejaron a Blum que se dejara arrastrar al conflicto español. De la virulencia de la prensa de derechas, inflamada por las noticias de los asesinatos masivos cometidos por las izquierdas en España, puede dar idea un artículo publicado el 25 de julio por el escritor católico FranÇois Mauriac que advirtía al gobierno que si se probara su colaboración en la matanza española ello podría empujar a los más moderados hacia la violencia. En el consejo celebrado ese mismo día el gobierno optó por renunciar al envío de armas francesas a España. Blum pensó entonces en recurrir a mandarlas a través de terceros países, en concreto México, que se prestaba a ello. Finalmente el 1 de agosto, el gobierno acordó proponer reglas comunes de no intervención tanto a Italia como a Gran Bretaña, pero en vista de las pruebas de que los italianos estaban enviando armas a los rebeldes, reasumió entre tanto su libertad de acción respecto a la ayuda a España ${ }^{15}$.

Al mismo tiempo, menudearon en aquellos dias de agosto los mitines en los que el ala izquierda del Frente Popular, representada por líderes comunistas como Maurice Thorez y Jacques Duclos, socialistas de la tendencia minoritaria como Jean Ziromski y sindicalistas de la CGT como Leon Jouhaux, presionaban al gobierno para que ayudara a España. Desde un punto de vista distinto, el embajador en España Jean Herbette, que pronto cambiaría de opinión, envió el 2 de agosto un despacho en el que argumentaba que frente al doble peligro que para los intereses franceses suponía que España se hundiera en la anarquía o se estableciera en ella una dictadura militar, la sóla garantía era la presencia de un gobierno a

${ }^{14}$ Les Événements survenus en France de 1933 a 1945, vol. I, Paris, PUF, 1951, págs. 215 y ss. (testimonio de L. Blum, 27-7-1947); Documents Diplomatiques Français, 1932-1939, 2. serie (en adelante $D D F$ ), Paris, Imprimerie Nationale, vol. III, doc. 34, Delbos a Herbette, Paris 26-7-36. LITTLE, D., Malevolent Neutrality: the United States, Great Britain and the origins of the Spanish Civil War. Ithaca, Cornell University Press, 1985, págs. 233.

${ }^{15}$ Renouvin, P. et Remond, R., (eds.), León Blum Chef de Gouvernement. París, FNSP, 1981, págs. 407-9 (carta de Fernando de los Ríos a Giral, París 25-7-36). Lebrun, A., Temoignage, París, Plon, 1946, pág. 244. DDF, III, 33, Delbos a Auriol, París 26-7-36. Lefranc, G., Histoire..., pág. 187. DDF III 46, Peyrouton a Delbos, 30-7-36. DDF III 66, Delbos a Auriol, Paris, 3-8-36. 
la vez democrático y fuerte. «Este gobierno -escribió- no puede ser actualmente más que el de Madrid. El apoyo a dársele debe ser evidentemente mesurado y presentado de manera que no haga aparecer a este gobierno como protegido del extranjero y no dar pretexto de intervención abusiva en sentido inverso» ${ }^{16}$.

Por entonces Blum intentó una gestión especial con Londres, por sugerencia del laborista británico Noel Baker, quien le hizo ver la conveniencia de que los argumentos de los militares franceses preocupados por la intervención italiana y alemana se oyeran en Londres. Con este fin envió al almirante Darlan, jefe de gabinete del ministro de Marina, quien el 5 de agosto se entrevistó con el almirante británico Chatfield. Este se mostró escéptico ante los temores franceses de que los italianos se instalaran en las Baleares y los alemanes en Canarias. Darlan dijo que era importante que no se facilitara «de ninguna manera el triunfo de los elementos nacionalistas españoles». Por su parte el primer Lord del Almirantazgo, Sir Samuel Hoare, al ser informado de la gestión, escribió que no se debia hacer nada que alentara al comunismo en España ${ }^{17}$.

Diversos testimonios concuerdan en que Léon Blum era partidario de ayudar a la República española y sólo renunció a ello forzado por las circunstancias. Según narró años después, tuvo incluso la tentación de dimitir y si no lo hizo fue por que le convencieron sus amigos socialistas españoles, relato que ha sido confirmado por uno de éstos ${ }^{18}$. Ello debió ocurrir pocas horas antes de la decisiva reunión de los ministros que tuvo lugar el 7 de agosto, en la que se optó de nuevo por prohibir el envío de armas a España. En dicha reunión, cuyas conclusiones fueron ratificadas en el consejo del día 8, las opiniones fueron contrapuestas. Al parecer cinco ministros socialistas se pronunciaron a favor de enviar armas a España y seis en contra, incluido Blum, cuatro radicales se manifestaron a favor, incluido Cot, y cuatro en contra, incluido Delbos. Mientras los ministros discutían, estaban despegando los aviones dispuestos para España, y Blum prolongó deliberadamente el debate hasta que se le hizo saber que había partido el último ${ }^{19}$.

Previamente, el mismo día 7, se había producido una visita del embajador británico Sir George Clerk al ministro de Exteriores Delbos, en la

${ }^{16}$ Public Record Office, Kew, FO 371/20526, 20527 y 20528, informes del embajador británico en París. MAE París, Z Esp 169, págs. 3-5, Herbette, 2-8-36.

${ }^{17}$ Kew FO 371/20527, Almirantazgo, 5-8-36. DDF III 87, Decoux, Londres, 5-8-36.

${ }^{18}$ Renouvin et Remond, Leon Blum..., págs. 409-411: testimonio de Jiménez de Asúa.

${ }^{19}$ Dreifort, Yvon Delbos..., pág. 49. Moch, Jules, Rencontres avec Leon Blum. París, Plon, 1970, págs. 198-200 
que tras haber planteado la duda de si el gobierno de Madrid no era sólo la pantalla tras la cual los anarquistas más extremos dirigian la situación, le pidió que hiciera lo posible para limitar y retrasar los envíos hasta que se llegara a un acuerdo. Luego, de manera "enteramente personal» y «bajo su propia responsabilidad», le advirtió acerca del peligro de cualquier acción que pudiera definitivamente comprometer al gobierno francés con un bando del conflicto y hacer más difícil la estrecha cooperación entre Gran Bretaña y Francia que requería la crisis. El Foreign Office aprobó esta gestión del embajador, que según un miembro de la embajada, Lloyd Thomas, podía haber sido el factor que decidió el resultado del debate en el seno del gobierno francés. Con anterioridad a ella, el director de asuntos políticos y comerciales del Quai d'Orsay, Bargeton, le había dicho a Thomas que la posición de Delbos y demás ministros opuestos al apoyo a España era débil y que cualquier cosa que los británicos pudieran hacer para reforzarla sería muy bien recibida ${ }^{20}$.

En el Foreign Office existía en aquellos momentos una gran preocupación, tanto por los sucesos de España como por su repercusión en Francia. Se temía que la guerra española provocara la división de Europa en dos bloques ideológicos, fascista y comunista, ambos opuestos al sentir predominante en Gran Bretaña. Sin embargo se tenía confianza en Blum. Según un informe enviado el 8 de septiembre por la embajada en Paris la politica española del gobierno Blum demostraba que no estaba dominado por los comunistas. Existía un peligro de subversión, pero los comunistas no parecian haber adquirido influencia en las fuerzas armadas, ni siquiera en las del aire. «A pesar de los esfuerzos de Mister Cot», según el informe ${ }^{21}$. Esa alusión a Cot resulta intrigante, ya que el ministro del Aire pertenecía a un partido que era el más moderado del Frente Popular, aunque en recuerdo de otros tiempos se seguía llamando radical, en el que convivían gentes de contrapuestos puntos de vista políticos, pero cuya prensa de todas las tendencias apoyó unánimemente la no intervención. El ministro de Educación Jean Zay, miembro también del ala izquierda del partido radical, destacó también en la defensa de la ayuda a la República española, pero el caso de Cot fue especialmente relevante, pues fue uno de los artífices del suministro clandestino de armas a España ${ }^{22}$.

A lo largo del mes de agosto, los acontecimientos tendieron a desacreditar al gobierno de Madrid, aparentemente incapaz de controlar a sus

${ }^{20}$ Kew Fo 471/20531, Lloyd Thomas. Paris, 11-8-36.

${ }^{21}$ Kew Fo 371/19859, Clerk. Paris 8-9-36.

${ }^{22}$ Sobre los radicales franceses y la guerra española: BernsteIn, $S$., Histoire du Parti Radical: II, crise du radicalisme, 1926-1939. Paris, FNSP, 1982, págs. 452-453. 
propios partidarios. El día 10 el embajador Herbette, que junto a la mayoría de sus colegas se habia instalado en el lado francés de la frontera, en San Juan de Luz, describia una situación en la que en cada municipio un comité que pretendía representar al Frente Popular se consideraba poco menos que soberano, en la que los anarcosindicalistas adquirian una influencia creciente y en la que por tanto la victoria militar se hacía imposible. La conclusión de Herbette era durísima: «seria bueno advertir al embajador de España en Paris que nos encaminamos hacia un estado de cosas en el que nos será imposible a nuestro gran pesar reconocer al gobierno de Madrid por la simple razón de que de hecho este gobierno habrá dejado de ejercer cualquier autoridad" ${ }^{23}$. Los asesinatos, cometidos abierta y masivamente, dañaron particularmente el crédito republicano. La prensa de derechas los difundia en todos los países y los informes de los diplomáticos los confirmaban. El 13 de agosto el encargado de negocios francés Bonjean informaba desde Madrid que, sabiendo que las autoridades no podian reprimirlos, los anarcosindicalistas (grupo al que los observadores extranjeros tendian a considerar como los principales culpables) cometian crimenes odiosos, cuyas victimas, entre las que se incluian religiosos, aristócratas, fascistas y empresarios, se podían evaluar en unas 1.200 sólo en la capital. Aunque por el momento las atrocidades cometidas por el bando rebelde fueron menos destacadas en los informes diplomáticos, en parte por el simple hecho de que había muy pocos diplomáticos en el territorio controlado por aquel, tampoco pasaron despercibidas. Herbette informó a fines de agosto de la matanza de 200 presos en Pamplona, y destacó que desgraciadamente el clero se asociaba en su gran mayoria a tales excesos ${ }^{24}$.

A finales de agosto, los distintos gobiernos europeos, con la excepción todavia del portugués, habían aceptado la propuesta francesa de no intervención, lo que hizo posible que el 9 de septiembre se constituyera en Londres un comité internacional encargado de controlar su aplicación. Tras la primera sesión del Comité el principe Bismarck, encargado de negocios alemán en Londres, comunicó a Berlín su impresión de que para Francia e Inglaterra "no se trataba tanto de tomar inmediatamente medidas efectivas como de apaciguar los ánimos excitados de los partidos de izquierda de ambos paises mediante la propia creación del comité» ${ }^{25}$. En realidad se demostraria con el tiempo que los gobiernos británico y fran-

\footnotetext{
${ }^{23}$ MAE París, Z, Esp 169. Herbette, San Juan de Luz, 10-8-36.

${ }^{24}$ MAE París, Z, Esp 169, Bonjean, Madrid 13 de septiembre de 1936; Herbette, San Juan de LuZ, 28-8-36.

${ }^{25}$ WATKINS, K. W., Britain divided: the effect of the Spanish Civil War on British opinion. Westport, Greenwood Press, 1976, pág. 92.
} 
cés no iban a esforzarse demasiado en que efectivamente no hubiera intervención, pero la impresión del diplomático alemán parece exagerada: el propósito inicial francés incluía realmente evitar la ayuda italiana y alemana a los rebeldes.

Apaciguar a la oposición interior era también importante para el gobierno francés, ya que a principios de septiembre la cuestión española, objeto de una gran campaña de agitación encabezada por los comunistas, parecia que iba a conducir a la ruptura del Frente Popular. No obstante, coincidiendo con la constitución del comité de Londres, ese peligro disminuyó. El 9 de septiembre el secretario general del Partido Comunista Francés, Maurice Thorez, excluyó públicamente la posibilidad de una ruptura. En opinión de la embajada británica, el gobierno salió reforzado de la marcha atrás del Partido Comunista en el tema español. Meses después un informe de dicha embajada sostendría incluso que la popularidad del partido se había visto perjudicada por su campaña en favor de España, que había sido percibida como una amenaza para la paz ${ }^{26}$.

En septiembre de 1936 las principales decisiones que guiarían la política francesa hacia España hasta el final del conflicto habian sido ya tomadas. Sin embargo la guerra se prolongó todavía durante dos años y medio, durante los cuales el gobierno francés se atuvo a la política de no intervención, que indudablemente tuvo al apoyo mayoritario de la opinión, lo que no evitó que el tema fuera objeto de un apasionado debate entre izquierdas y derechas ${ }^{27}$. Eso no significa que la actitud francesa fuera meramente pasiva, como se expondrá en las páginas siguientes, en las que se abordarán dos cuestiones: la destacada contribución del Partido Comunista Francés a la ayuda que la Komintern prestó a la República española y los vaivenes del gobierno francés respecto al paso clandestino de envíos militares a través de su frontera.

\section{EL PARTIDO COMUNISTA FRANCÉS Y LAS BRIGADAS INTERNACIONALES}

Los orígenes de la decisión soviética y comunista de apoyar a la República española siguen envueltos en la oscuridad, pero hay indicios de

\footnotetext{
${ }^{26}$ Kew FO 371/19859, "Memorandum respecting Internal Affairs in France during the third quarter of 1936»; 371/20685, «Memorandum respecting Internal Affairs in France during the first quarter of $1937 \%$.

${ }^{27}$ Véase: Gordon, Richard Alan, France and the Spanish Civil War. Ann Arbor, University Microfilms International, 1971, págs. 103-415.
} 
que los franceses jugaron un papel importante en la decisión de la Komintern de organizar las Brigadas Internacionales ${ }^{28}$. Según Louis Fischer, un norteamericano bien relacionado en medios comunistas internacionales, fue el secretario general del PCF, Maurice Thorez, quien más insistió en medios moscovitas para que la URSS enviara suministros militares a España y que la Internacional organizara una unidad de voluntarios extranjeros bajo su control ${ }^{29}$. En todo caso es indudable que, tomada la decisión, el papel principal en la organización de las Brigadas internacionales correspondió al PCF. El centro de la operación se estableció en París, bajo la dirección del diputado André Marty, ayudado por comunistas extranjeros. Inicialmente los comunistas trataron de mantener en secreto su participación y dar a la operación un tono frentepopulista. Sólo tras el éxito de la defensa de Madrid se empezó a reconocer más abiertamente el carácter comunista de las Brigadas. Desde entonces, adecuándose a la audiencia a la que se dirigía, la propaganda procuró tanto atribuir al comunismo la gloria de las Brigadas como presentarlas como un fenómeno espontáneo de solidaridad antifascista.

Desde noviembre de 1936, las autoridades francesas estaban informadas por sus servicios policiales de que se habia organizado en Francia un reclutamiento metódicamente organizado, con salidas regulares desde distintos puntos, prima de alistamiento y oferta de pensiones para las familias en caso de fallecimiento. El pasaje de la frontera se hacía clandestinamente, pero sin excesivas dificultades ${ }^{30}$.

Los primeros reclutas de las Brigadas Internacionales, que no deben ser confundidos con los voluntarios extranjeros que en pequeño número se habian incorporado previamente a las milicias españolas, llegaron a mediados de octubre. Su base de instrucción se situó en Albacete, bajo control de la Komintern, cuyo principal representante era André Marty. El papel que en 1919, siendo un joven marinero, habia jugado éste en el motín de la flota francesa que operaba contra los bolcheviques en el Mar Negro, que le costó año y medio de prisión, le había convertido en un héroe comunista en Francia y en la Unión Soviética. Partidario de una rígida disciplina y muy desconfiado, se creó la reputación de fusilar a voluntarios internacionales por el delito de disidencia política, bajo la eti-

\footnotetext{
${ }^{28}$ Serrano, Carlos, L'Enjeu espagnol: PCF et guerre d'Espagne. Paris, Messidor, 1987, págs. 47-57.

${ }^{29}$ Richardson, R. Dan, Comintern army: the International Brigades and the Spanish Civil War. Lexington, University Press of Kentucky, 1982, pág. 14. Los libros de Serrano y Richardson, desde una perspectiva respectivamente favorable y contraria a la linea comunista, son los más útiles sobre el tema.

${ }^{30}$ Richardson, Comintern..., págs. 31-46. DDF III, 512, 19-11-36.
} 
queta de trotskismo, lo que le valió el apodo de «el carnicero de Albacete». La primera de las Brigadas Internacionales entró en acción el 9 de noviembre, en el frente de Madrid ${ }^{31}$.

En un informe en el que resumia la actuación de las Brigadas Internacionales, el agregado militar francés, Morel, afirmaba que, tras jugar un papel destacado en las batallas en torno a Madrid que se produjeron desde noviembre de 1936 a febrero de 1937, su moral y sus efectivos empezaron a disminuir. El cansancio, los fallos en el mando, el choque de las nacionalidades, las represiones torpes y brutales en Albacete fueron, según Morel, factores que dieron origen a gran número de deserciones, lo que unido a la decisión del gobierno francés de impedir el cruce de la frontera por los voluntarios produjo a partir de febrero una disminución de efectivos. Por entonces el problema de los voluntarios internacionales que deseaban salir de España y se encontraban impedidos de hacerlo se había convertido en una de las principales preocupaciones de los consules franceses en Barcelona, Valencia y Alicante. Desde marzo se recurrió a voluntarios españoles para llenar los vacios de las Brigadas, al tiempo que una disciplina más inteligente y una vigilancia más severa acababan con las deserciones. Tales juicios de Morel resultan sustancialmente confirmados por estudios recientes ${ }^{32}$.

La importancia de las Brigadas Internacionales no estuvo en su número sino en su calidad y en su oportuna llegada cuando Franco estaba a punto de conquistar Madrid y cuando la organización de un Ejército Popular que sustituyera a las desorganizadas milicias estaba en sus comienzos. Morel estimaba que en su momento álgido los efectivos extranjeros de las Brigadas no superaban los 30.000 , de los que unos 12.000 serían franceses. El número de estos últimos tendía sin embargo a ser exagerado por el doble motivo de que muchos brigadistas eran extranjeros (alemanes, polacos, italianos) residentes en Francia, y de que bastantes franceses que entraron a España no lo hicieron para incorporarse a las Brigadas. Richardson por su parte estima que la máxima fuerza de las Brigadas se alcanzó en febrero de 1937, cuando disponían de unos

\footnotetext{
${ }^{31}$ Richardson, Comintern..., págs. 51-54 y 174-175. En la famosa novela de Hemingway sobre la guerra civil, publicada en 1939, un personaje comenta acerca de Marty: «todos saben que está loco" y que «tiene la manía de fusilar gente, siempre por motivos políticos": Hemingway, Ernest, Por quién doblan las campanas. Buenos Aires, Claridad, 1944, págs. 425426. Sin embargo recientemente se ha puesto en duda que las ejecuciones de brigadistas ordenadas por Marty fueran tan numerosas como se le achacaba: Serrano, L'Enjeu..., págs. 124-128.

${ }^{32}$ DDF VII, 1, Morel, Valencia 29-9-37, DDF V, 4, Delbos, Paris 20-2-37. Richaroson, Comintern..., págs. 81-89, 98-99 y 165-171.
} 
25.000 hombres, lo que teniendo en cuenta las bajas supondria la llegada de unos 30.000 voluntarios entre octubre de 1936 y febrero de 1937. Desde que en esta última fecha el gobierno francés cerró oficialmente la frontera, el paso se hizo más difícil y hubo que recurrir a los caminos de montaña, siendo detenidos algunos de los que lo intentaban, aunque la policía francesa no puso especial empeño en la cuestión ${ }^{33}$.

Las cifras dadas por dos historiadores españoles que han consultado documentación de las propias Brigadas, los hermanos Salas Larrazabal ${ }^{34}$, son algo superiores: 46.313 hombres llegados hasta marzo de 1937 y muy pocos más a partir de esa fecha, lo que supone que, dadas las bajas, sus efectivos habrian alcanzado un máximo de 35.000. En octubre de 1937, segun Morel, sólo quedarían en el ejército republicano unos 15.000 extranjeros, de los que el grupo nacional más numeroso seguía siendo el de los franceses, con 6.000. Un año después el gobierno republicano decidiría la repatriación de los voluntarios.

Al envio de voluntarios hay que sumar otra importante aportación del PCF: la creación en abril de 1937 de una compañia naviera, France-Navegation, destinada al tráfico encubierto de armas con destino a España ${ }^{35}$.

\section{LA «NO INTERVENCIÓN ATENUADA»}

A diferencia de Italia y Alemania, Francia siempre se opuso a convertir el acuerdo de no intervención en una farsa y si bien acudieron bastantes voluntarios franceses, nunca fueron enviadas tropas regulares. En cuanto a los suministros de armamento francés, fueron reducidos. Respecto a los aviones, un arma particularmente importante y relativamente fácil de

${ }^{33}$ DDF VII, 139, Payart. Valencia 26-10-37. Richaroson, Comintern..., pág. 46.

${ }^{34}$ Salas Larrazabal, R. y J. M., Historia general de la guerra de España. Madrid, Rialp, 1986. DDF VII, 106, Payart, Valencia 19-10-37. Un informe de los servicios de información de Franco calculaba que el número de combatientes que habian cruzado la frontera francesa ( $\sin$ contar los que habian pasado por pasos de montaña o por via maritima) habia sido de 25.349 entre octubre de 1936 y marzo de 1937 y de 25.147 desde abril de 1937 hasta agosto de 1938: Ministerio de asuntos Exteriores, Madrid (en adelante MAE Madrid) R 1047/45: «Paso de personal por la frontera franco-catalana desde el principio de la Campaña hasta agosto 1938\%. Estas cifras no son sin embargo válidas, ya que incluyen a los españoles residentes en Francia que se incorporaban a filas. Según otro informe de la misma fuente, la mayoría de quienes cruzaron la frontera en julio y agosto de 1938 eran "movilizados", es decir con seguridad españoles.

${ }^{35}$ Grison, D. y Hertzog, G., Les Brigades de la mer. París, Grasset, 1979. 
cuantificar, Jesús Salas Larrazabal ha evaluado en 140 los enviados por Francia a la República española, 99 de los cuales lo habrían sido en 1936 y ninguno después de marzo de 1938 (fecha en que Cot dejó de ser ministro). Eran muy pocos comparados con los 1.249 que Alemania e Italia proporcionaron a Franco y los 1.008 que la Unión Soviética suministró a la República, según el mismo autor, pero es que además tales cifras han sido revisadas a la baja, tras una minuciosa investigación, por Gerald Howson. Los tipos de aviones militares más importantes suministrados por Francia fueron los cazas Dewoitine 371 y 372 , de los que se enviaron trece el mismo 8 de agosto de 1936 y otros tantos durante el resto de la guerra (lo que da un total de 26 frente a los 42 estimados por Salas) y los bombarderos Potez 54, de los que seis se enviaron el 8 de agosto de 1936, ocho más durante el resto de ese año y cuatro en octubre de 1937 (lo que da un tal de 18, frente a los 40 estimados por Salas). Otros datos importantes aportados por Howson son que ningún avión militar francés se envió antes del 8 de agosto y que los 19 enviados ese día carecían de armamento, que hubo de ser tomado de los depósitos españoles, e iban pilotados por un improvisado grupo de mercenarios y voluntarios idealistas, bajo el mando nominal del escritor André Malraux, que no era un aviador profesional ${ }^{36}$.

En realidad la contribución de Francia a la resistencia republicana consistió sobre todo en que, en contra del compromiso de no intervención, permitió el paso a través de su territorio de suministros militares procedentes de terceros paises, especialmente de la Unión Soviética. El propio Blum ${ }^{37}$ confesaría años después que, tras haber comprobado que otros países no respetaban los compromisos de no intervención: «tuvimos que adoptar nosotros también el sistema de la no intervención atenuada, o sea que, voluntaria y sistemáticamente, hemos cerrado los ojos sobre el contrabando de armas, e incluso, a partir de cierto momento, lo hemos casi organizado». Otros de los protagonistas de la operación han sido más explícitos. Jules Moch ha explicado como durante el gobierno Blum los envíos clandestinos eran coordinados por Gaston Cusin, del gabinete del ministro de Finanzas Vincent Auriol, por Jean Moulin, el futuro héroe de la Resistencia, director de gabinete de Cot en el ministerio del Aire, y

36 Salas LaRRAzABal, Jesús, Intervención extranjera en la guerra de España. Madrid, Ed. Nacional, 1974, págs. 446 y 449. Howson, Gerald, Aircraft of the Spanish Civil War. Londres, Putnam, 1990, págs. 13, 110-113 y 252-254.

${ }^{37}$ Les evenements..., págs. 215 y sigs.: testimonio de Leon Blum. Moch, Recontres..., págs. 204-206. Blumé, Daniel. (ed.), "Contribution à l'histoire de la politique de non-intervention", Cahiers Léon Blum, 2-3 (1977-1978), págs. 80-82: testimonio de Gaston Cusin. ReNOuvIN ET REMOND, Leon Blum..., págs. 368-369: testimonio de Pierre Cot. 
por él mismo, en la secretaría general de Blum. Gaston Cusin, que provenia del cuerpo de aduaneros, donde había sido un activo militante sindical, ha afirmado que el aparato para los envíos clandestinos fue puesto en marcha por el propio Blum poco después de la prohibición oficial del 8 de agosto, estuvo coordinado por unas pocas personas para mantenerlo en secreto y siguió funcionando, a pesar de los cambios de gobierno, durante toda la guerra. Él estaba en contacto con el Partido Comunista Francés a través de su tesorero Dutilleul, con la Internacional Comunista en Madrid a través del húngaro Geroe, y con la Internacional en París a través del italiano Cerretti, así como con algunos responsables del ministerio de la Guerra y el del Interior. Su principal misión fue facilitar el paso de los envios soviéticos a través de Francia. «En la práctica, -indica Cusin- no se envió material francés, salvo Cot».

Durante el primer año de la guerra los envíos soviéticos se hicieron por vía marítima directa a través del Mediterráneo, pero durante el verano de 1937 la acción de la flota de Franco y de submarinos «desconocidos», de los que era bien sabido que eran italianos, hizo muy peligrosa esta ruta. La conferencia de Nyon celebrada en septiembre de 1937, a instancias de Gran Bretaña y Francia, para poner fin a la acción de los submarinos «piratas", no sirvió para tranquilizar a los soviéticos, que se indignaron al comprobar como se invitaba a Italia a participar en la patrulla naval destinada a impedir los ataques. Dado que la desaparición de los suministros soviéticos habría supuesto el fin de la resistencia republicana, se hizo imperativo encontrar otra ruta alternativa, que sólo podía consistir en envíos maritimos desde los puertos del Báltico a los del Atlántico francés, donde los suministros serian reexpedidos por tierra. Inicialmente hubo presiones, tanto francesas como españolas, sobre el nuevo gobierno presidido por el radical Chautemps, para la reapertura oficial de la frontera francesa a todo tipo de tráfico con España. Cuando, en parte por oposición británica, esto no resultó viable, se optó por el paso clandestino a través del territorio francés. Cusin organizó entonces el tráfico de material soviético de Dunkerque a Perpignan en convoyes sellados, con un aduanero en el primer camión para marcar la extraterritorialidad. Según el embajador español en Londres, el secretario del Foreign Office, Anthony Eden, habría dicho a los franceses que dejaran pasar lo que quisieran, pero que no abrieran oficialmente la frontera. Es obvio que esto último habría tenido un significado político mucho mayor que la simple tolerancia hacia el tráfico ilegal, por lo que no es extraño que un ministro francés enemigo de complicaciones en España, le expresara al embajador británico su admiración por la manera en que el gobierno de Su Majestad había sabido mantener al de París en la dirección correcta respecto al conflicto español ${ }^{38}$.

38 Salas Larrazabal, R. Y J. M., Historia general..., 537-539. Haslam, Jonathan, The Soviet 
Durante el efímero gobierno Blum de marzo-abril de 1938, que coincidió con la ofensiva franquista que cortó en dos el territorio republicano, se planteó y rápidamente descartó, una ayuda más efectiva a España ${ }^{39}$. El gobierno que le sucedió, con dos radicales, Daladier y Bonnet, en la Presidencia y en asuntos exteriores, suscitó las máximas esperanzas en el agente de Franco en París, Quiñones de León, pero durante varias semanas mantuvo la frontera abierta a un intenso tráfico clandestino. Finalmente el 13 de junio la tolerancia hacia el mismo terminó. Según explicó el secretario general del Quai d'Orsay a un corresponsal de The Times, el Gobierno francés habia cerrado la frontera pirenaica sólo como resultado de la constante presión británica, aunque literalmente no hubiera habido una gestión formal en ese sentido. Los servicios de información franquistas registraron a partir de entonces un gran descenso en los suministros llegados a la República desde Francia, aunque no desaparecieron los envíos por via marítima ${ }^{40}$.

La frontera se reabrió por unos días al tráfico clandestino en enero de 1939, cuando ya era demasiado tarde ${ }^{41}$. Poco después, mientras que el gobierno francés se apresuraba a entablar relaciones con el bando vencedor ${ }^{42}$, la frontera pirenaica sería testigo del éxodo hacia Francia de cientos de miles de republicanos españoles ${ }^{43}$. Aunque los peores temores franceses no se confirmaron, ya que la España franquista no permitió bases italianas ni alemanas en su territorio y permaneció estrictamente

Union.., págs. 147-8. DDF VI, 475, Massigli. Ginebra 20-9-37. Anso, Mariano, Yo fui ministro de Negrín. Barcelona, Planeta, 1976, pág. 204, Renouvin et Remond, Leon Blum..., pág. 371: testimonio de Jules Moch. Kew FO 371/21611: France: Annual Report 1937. AzCARATE, Pablo de, Mi embajada en Londres durante la guerra civil española. Barcelona, Ariel, 1976, págs. 213-215.

${ }^{39}$ DDF VIII, 446, Comité Defensa Nacional, 15-3-38; 449, entrevista del ministro con el embajador británico, 16-3-38. MARTinez PARRILla, Jaime, Las fuerzas armadas francesas ante la guerra civil española. Madrid, eds. Ejército, 1987, págs. 192-198. AzCarate, Mi embajada..., págs. 356-62.

${ }^{40}$ MAE Madrid, R 1057/8, Quiñones. Paris 11-4-38. Kew FO 371/21591, McDonald, a The Times, 6-7-38. MAE Madrid, R 1047/44 y 45. ViÑAs, Angel, "Las relaciones hispano-francesas, el gobierno Daladier y la crisis de Munich", en Españoles y franceses..., págs. 161-220.

${ }^{41}$ AvILÉS FARRE, Juan, "Las grandes potencias y el final de la República», en Historia 16. La Guerra Civil, 23, 1988, págs. 86-96.

${ }_{42}$ Borras Llop, Jose María, "Relaciones entre los gobiernos de París y Burgos al final de la guerra civil española: la firma del convenio Jordana-Bérard", en Estudios sobre historia de España. Homenaje a Manuel Tuñón de Lara. Madrid, UIMP, 1981, vol. II, págs. 297306.

${ }^{43}$ Stein, Louis, Beyond Death and Exile. The Spanish Republicans in France, 1939-1946. Cambridge, Mass., Harvard University Press, 1979. RuBıo, Javier, «Los españoles en Francia, hacia Francia y desde Francia", en MiLza, P. ET PeschanskI, D. (eds.), Italiens et espagnols en France, 1938-1946. París, CNRS, 1991, págs. 27-37. Sagnes, J. et Caucanas, S. (eds.), Les français et la guerre d'Espagne. Université de Perpignan 1990, págs. 183-250. 
neutral hasta la derrota de Francia, la hostilidad del nuevo régimen español hacia ésta era inconfundible ${ }^{44}$. La conclusión a la que llegó el ministro Jean Zay, un radical de izquierda partidario de la ayuda a España, puede ser aceptada. «Intervinimos -escribió - bastante para que nos lo reprochara el bando contrario, pero no lo suficiente para dar a los republicanos una ayuda eficaz" ${ }^{45}$.

En definitiva la política francesa pecó de indecisión y ambigüedad, pero dadas las circunstancias hubiera sido muy dificil para cualquier gobierno francés adoptar otra. La propia división de la opinión fue probablemente el factor que más contribuyó al resultado, pero la necesaria dependencia de París hacia un aliado británico entregado a la política de apaciguamiento de los dictadores pesó también. Ello hizo posible que en un país en que la influencia franco-británica había sido hasta entonces predominante se combatiera una guerra civil en que ambos bandos estaban apoyados respectivamente por las potencias fascistas y por la Unión Soviética, quedando relegadas ambas potencias occidentales a un papel de poco más que espectadores.

La guerra civil española proporcionó a la literatura francesa una gran novela: L'espoir de André Malraux (1937). Es un libro lleno de admiración hacia el sentido de la disciplina y de la eficacia de los comunistas, únicos capaces de transformar "nuestro Apocalipsis en un ejército", pero que no elude la dolorosa contradicción entre al apego a los valores humanos individuales y el sacrificio de los mismos en aras de una línea politica: «para un hombre que piensa, la revolución es trágica». Por todo ello es una obra emblemática de un momento de crisis, en que el aparente declive de las democracias condujo a un sector importante de la intelectualidad occidental a ver en el activismo heroico de los comunistas la sola esperanza de un futuro mejor. "Nosotros, demócratas, -afirma uno de sus personajes-, creemos en todo menos en nosotros mismos. Si un Estado fascista o comunista dispusiera de la fuerza de los Estados Unidos, de Inglaterra y de Francia reunidas, estariamos aterrorizados. Pero como es nuestra fuerza, no creemos en ella" ${ }^{46}$. Es un juicio adecuado acerca del efecto conjunto del aislacionismo norteamericano, de la política británica de apaciguamiento y de la indecisión francesa, que hizo a las democracias de los años treinta inoperantes ante conflictos como el español.

44 AVILES FARRE, Juan, "Lequerica, embajador franquista en París», Historia 16, 1989, págs. $12-20$.

45 ZAY, Jean, Souvenirs et solitude. París, Julliard, 1946, págs. 114-115.

46 Malraux, André, La esperanza. Barcelona, EDHASA, 1978, págs. 210, 384 y 374. 


\title{
La política británica ante la guerra civil española
}

\author{
EnRIQUe MoRadiellos
}

En enero de 1939, cuando el colapso republicano en Cataluña anunciaba el final de la guerra civil, Sir Robert Vansittart, Primer Consejero Diplomático del Foreign Office, enjuiciaba en un memorándum interno el efecto de la política británica en el conflicto del siguiente modo:

el curso entero de nuestra política de No Intervención - que en realidad, como todos sabemos, operó de un modo completamente partidista - ha estado favoreciendo la victoria de Franco ${ }^{\text {. }}$

$Y$, ciertamente, es indudable que la inamovible adhesión británica al Acuerdo de No Intervención firmado por los gobiernos europeos en agosto de 1936 tuvo implicaciones diferentes para ambos bandos españoles. En primer lugar, porque dicho Acuerdo prescribía un embargo de armas a los contendientes sin reconocimiento paralelo de sus derechos de beligerancia, constituyendo así un tipo de neutralidad sui generis, que combinaba el respeto jurídico al status del gobierno reconocido con su equiparación a los rebeldes en términos operativos. En segundo lugar, porque esa política neutralista permaneció inalterada a pesar del continuo apoyo italo-germano a los insurgentes, deviniendo así en una tolerancia implicita hacia el sabotaje de la No Intervención practicado por las potencias fascistas.

Habida cuenta del perjuicio que la política británica ocasionó a la República, no es extraño que la izquierda europea en general, y el laborismo en particular, atribuyese la misma a una motivación partidista: la hos-

Memorándum, 16-I-1939. Archivo del Foreign Office, serie 371 (General Correspondence), legajo 24115, documento W973. En adelante: FO 371/24115 W973. Todos los archivos británicos citados se hallan en el Public Record Office (Kew, Surrey). 
tilidad encubierta de un gobierno británico de mayoria conservadora frente a un gobierno español envuelto en un proceso revolucionario. Por su parte, los medios oficiales británicos siempre rechazaron tal acusación y justificaron su conducta con imponentes motivos de orden internacional: la necesidad suprema de confinar la guerra en España y evitar su conversión en un conflicto europeo. Como veremos, ambos argumentos tienen su parte de razón y puede afirmarse que la formulación y ejecución de la política británica en el conflicto obedeció tanto a una aguda prevención antirrevolucionaria como a la necesidad de adaptarse a los objetivos generales de la política de apaciguamiento europeo.

El papel de la prevención antirrevolucionaria en la génesis de la actitud británica se refleja claramente en la atención prestada por el Foreign Office a la evolución socio-política española durante el quinquenio republicano. El objeto de dicha atención era sobre todo la vigilancia y salvaguardia de los cuantiosos intereses británicos radicados en el país: 1. ${ }^{\circ}$ ) la base naval de Gibraltar, pieza clave para la hegemonía británica en el Mediterráneo y las comunicaciones con la India, cuya seguridad requería como primera condición la benevolencia del hinterland español; $2^{\circ}$ ) la destacada participación británica en el comercio exterior de España, puesto que Gran Bretaña absorbía el 25 por 100 de las exportaciones españolas y proporcionaba el 10 por 100 de las importaciones; y $3 .^{\circ}$ ) el gran volumen de las inversiones británicas en el país, que representaban un 40 por 100 de todas las existentes y se concentraban en la mineria de piritas y del hierro, sectores de enorme importancia para la industria británica, especialmente la de armamento ${ }^{2}$.

En general, desde la proclamación de la República, el Foreign Office había abrigado serias dudas sobre la capacidad de las autoridades reformistas para estabilizar las agudas tensiones socio-políticas existentes. Sin embargo, fue a partir de febrero de 1936, con la llegada al poder del Frente Popular, cuando comenzó a cobrar forma en los medios oficiales británicos una interpretación precisa de la crisis española, auténtica mimesis de la situación rusa entre febrero y octubre de 1917. A tenor de esta interpretación, España había entrado en una fase de tipo "Kerenski», con el gabinete republicano progresivamente desbordado por la propia movilización popular que le había encumbrado, registrándose un deslizamiento hacia una situación de doble poder prerrevolucionaria y probablemente fomentada por la Comintern. A la par que se llegaba a esta

\footnotetext{
${ }^{2}$ Véase una exposición ampliada sobre estos intereses en Moradiellos, E., Neutralidad Benévola. El gobierno británico y la insurrección militar española de 1936 (Oviedo 1990), caps. 1 y 2 .
} 
conclusión, el Foreign Office recibió noticias fidedignas sobre una extensa conspiración militar destinada a restaurar el orden, sin otros propósitos de índole fascista, lo que permitía confiar en un desenlace de la crisis que atajase la repetición de la secuencia revolucionaria rusa en la otra esquina del continente ${ }^{3}$.

La cristalización de esta lectura de la crisis española, que tuvo lugar en torno a junio de 1936, fue coetánea con el inicio de la política de apaciguamiento de la Italia fascista, simbolizado por la anulación de las sanciones económicas impuestas a raíz de la invasión italiana de Abisinia. Desde esa fecha, el objetivo primordial de la diplomacia británica consistiría en restaurar la armonía política con Italia en el Mediterráneo, a fin de evitar su alineamiento con los otros dos Estados revisionistas y potencialmente hostiles al imperio británico: la Alemania nazi en Europa central y el Japón en el Extremo Oriente. Este objetivo primordial estaba exigido por la impreparación militar ante una posible guerra en tres frentes dispersos y por el deseo de atajar una carrera armamentista cuyo coste financiero pondría en peligro la incipiente recuperación económica y la estabilidad socio-política de la metrópoli y del Imperio ${ }^{4}$. Por consiguiente, en vísperas de la tormenta española, la prevención antirrevolucionaria y la búsqueda de una entente mediterránea con Italia eran ya conceptos conjugados en los análisis diplomáticos del Foreign Office.

Desde el inicio de la insurrección militar el 17 de julio de 1936, Londres fue recibiendo noticias sobre el carácter de los bandos en conflicto que concordaban plenamente con sus informes previos. Así, fuentes de la embajada británica certificaron de inmediato que, en España, «hoy no existía ningún gobierno. De un lado estaban actuando fuerzas militares y de otro se les oponía un Soviet virtual». Por su parte, el comandante de Gibraltar advirtió: «Si las fuerzas del gobierno, que son prácticamente comunistas, ganan la partida, puede presentarse peligro para los súbditos británicos» ${ }^{5}$. En consecuencia, el Foreign Office interpretó la sublevación como la fase resolutiva de la prolongada pugna entre fuerzas revolucionarias y contrarrevolucionarias, cuyo choque frontal habia arrumbado al gobierno reformista a la función de mero comparsa impotente y legitimador de las primeras. $Y$ aquí residia la gran diferencia entre el caso

\footnotetext{
${ }^{3}$ Op. cit., págs. $117-133$.

${ }^{4}$ SCHMIDT, G., The Politics and Economics of Appeasement. British Foreign Policy in the 1930 s (Leamington Spa 1984). KENNEDY, P., The Realities behind Diplomacy. Background Influences on British External Policy (London 1981). PratT, L., East of Malta, West of Suez. Britain's Mediterranean Crisis, 1936-1939 (Cambridge 1975).

${ }_{5}$ Telegramas del agregado comercial (Biarritz) y del contraalmirante Pipon (Gibraltar), 21-VI1-1936. FO 371/20523 W6755 y W6754.
} 
español y el ruso, origen de todos los problemas para la diplomacia británica: la legalidad formal republicana había quedado en el campo donde se desataria la temida revolución social, en tanto que la ilegitimidad formal se encontraba en el campo de la contrarrevolución.

Apenas formulado ese juicio, Londres tuvo que decidir su respuesta ante una petición republicana para que su flota pudiera repostar combustible en Gibraltar y continuar el bloqueo naval que impedía el traslado de las tropas marroquies a la Península. A la par, el general Franco habia transmitido una demanda opuesta: la neutralización de Gibraltar y la expulsión de la flota gubernamental. El 22 de julio, el gabinete británico decidió que «el gobierno español tenía derecho, por supuesto, a comprar petróleo de fuentes comerciales», aunque «tal circunstancia sería muy indeseable». Por tanto, el Foreign Office quedó encargado de poner en práctica «una política dilatoria por el momento» ${ }^{6}$. En definitiva, el gabinete adoptaba una neutralidad tácita, no proclamada formal y públicamente. Esta política dilatoria, en la medida en que respetaba el status jurídico del gobierno, era una solución provisional entre las dos alternativas existentes ante una guerra civil: $\left.1 .^{\circ}\right)$ la asistencia al gobierno reconocido, aceptando la vigencia de sus competencias legales, incluyendo el derecho de su flota a repostar en puertos extranjeros; $2 .^{\circ}$ ) la neutralidad entre dos beligerantes reconocidos y equiparados en sus derechos y deberes. Y la razón esencial para adoptar una política que descartaba el primer curso y preparaba prudentemente la adopción del segundo era doble: la certeza de que el gobierno no tenía fuerza para frenar la revolución latente en su retaguardia y el deseo de evitar la contingencia de ayudar a un bando cuya legalidad encubría un proceso revolucionario. Así se desprende del telegrama confidencial enviado a las autoridades de los Dominios después de la reunión ministerial:

Informes del cónsul general británico en funciones en Barcelona, donde las fuerzas gubernamentales han aplastado la rebelión, muestran que la situación es crítica dado que el gobierno parece estar a merced de los obreros armados?.

Consumada la neutralización de Gibraltar, Londres hubo de afrontar el peligro de internacionalización del conflicto generado por las peticiones

\footnotetext{
${ }^{6}$ Acta del gabinete, 22-VII-1936. Archivo del Gabinete (Cabinet Office Records), serie 23 (Cabinet Minutes \& Conclusions), legajo 85. En adelante: CAB 23/85. Minuta de Mr Seymour, 23-VII-1936. FO 371/20523 W6754.

Telegrama confidencial a los gobiernos Canadá, Australia, Nueva Zelanda, Unión de Sudáfrica y Eire, 23-VII-1936. FO 371/20525 W7223.
} 
españolas de ayuda exterior. No en vano, la perspectiva de un apoyo del aliado francés a la República y de una ayuda italo-germana a Franco planteaba graves amenazas para la política de apaciguamiento. Además, dada la naturaleza del bando republicano, se sospechaba que el apoyo francés potenciaria el comunismo y precipitaria una guerra europea que sólo habría de beneficiar a la Unión Soviética. Sir Maurice Hankey, el influyente secretario del gabinete, ya había advertido a sus colegas el 20 de julio sobre el particular:

En el estado actual de Europa, con Francia y España amenazadas por el bolchevismo, no es inconcebible que dentro de poco nos convenga unirnos a Alemania e Italia. Y cuanto más nos mantengamos alejados de complicaciones europeas, tanto mejor ${ }^{8}$.

Como es bien sabido, el conocimiento de esta opinión británica contribuyó poderosamente a refrenar la inicial disposición del gobierno frentepopulista francés en favor de la República, aunque fue su propia división interna lo que determinó el embargo de armas decretado el 25 de julio. Por el contrario, la actitud británica convenció a Hitler y Mussolini de que una ayuda limitada y encubierta a Franco no encontraría oposición enérgica en Londres y podria reportar notables ventajas políticas y estratégicas ${ }^{9}$. De hecho, la perspectiva de una intervención exterior en la contienda en nada modificó la posición británica, antes al contrario. El 26 de julio, el primer ministro, Stanley Baldwin, dictó a Anthony Eden, secretario del Foreign Office, una directriz política extraordinariamente clara en su simplicidad:

De ningún modo, con independencia de lo que haga Francia o cualquier otro pais, debe meternos en la lucha al lado de los rusos ${ }^{10}$.

En consecuencia, cinco días después, Eden implantó secretamente un embargo de armas a la República, a pesar de garantizar en el Parlamento la vigencia del derecho exclusivo del gobierno español a comprar armas en Gran Bretaña. Para entonces, las noticias sobre incautaciones y colec-

\footnotetext{
${ }^{8}$ Memorándum, 20-VII-1936. FO 371/20475 W11340. Hankey era secretario del Gabinete y del Comité de Defensa Imperial desde 1912.

"WARNER, G., «France and Non-Intervention in Spain», International Affairs, 38, 1962, págs. 203-220. Young, R., In Command of France. French Foreign Policy and Military Planning, 1933-1940 (Harvard 1978). SAZ, I., Mussolini contra la ll República (Valencia 1986). VINAS, A., La Alemania nazi y el 18 de julio (2." ed. Madrid 1977).

${ }^{10}$ Confidencia de Baldwin recogida por su amigo íntimo y ex-secretario adjunto del gabinete: JONES, T., A Diary with Letters, 1931-1950 (Oxford 1954).
} 
tivizaciones de propiedades británicas en zona republicana habian confirmado los peores presagios y demostrado, en palabras textuales de un funcionario del Foreign Office, "que la alternativa a Franco es el comunismo atemperado por la anarquía" ${ }^{11 .}$

En definitiva, a fines de julio de 1936, el juicio sobre la situación española que habia dictado la neutralidad tácita se había visto reforzado por cruciales consideraciones de política exterior. En nuestra opinión, la documentación coetánea y posterior, permite afirmar que para esas fechas los gobernantes británicos habian consumado la formulación progresiva y asistemática de una verdadera estrategia política ante un golpe militar devenido en guerra civil. La neutralidad tácita e incondicional era la manifestación externa de dicha estrategia, vertebrada sobre dos factores condicionantes y dos supuestos implícitos.

El primer factor lo constituía la prevención antirrevolucionaria. En consonancia, el temor principal residia en el triunfo de un bando gubernamental anegado por la revolución, tanto por sus efectos sobre los intereses británicos en España como por el peligro de que desencadenase un proceso de bolchevización en Europa. El pavor ante este doble riesgo dictó el completo desahucio del gobierno republicano e hizo preferible la victoria, cuanto primero mejor, de los insurgentes, a fin de conjurar el foco de tensión generado. Esta preferencia se basaba en la convicción de que el movimiento militar era políticamente inocuo, dado su carácter meramente contrarrevolucionario y el predominio del Ejército sobre las fuerzas fascistas. Por igual motivo, la contingencia de una ayuda limitada y encubierta italo-germana no provocó alarma especial ni atemperó el deseo de un triunfo rebelde. En la base de esta relativa tranquilidad se hallaba un supuesto económico sólidamente arraigado en los medios oficiales: la indispensabilidad del mercado comercial y financiero británico para la economía española en la etapa de reconstrucción postbélica. El hecho de que ningún otro país europeo, incluyendo a Italia y Alemania, estuviese en condiciones de financiar esa reconstrucción garantizaba al Reino Unido bases firmes para establecer relaciones cordiales con un régimen militar y contrarrestar influencias contrarias italo-germanas. En último término, si la diplomacia de la libra era insuficiente, siempre quedaba el resorte de la diplomacia de la cañonera: la superioridad de la Royal Navy y su capacidad de bloqueo.

El segundo factor condicionante era la situación interna en Gran Bretaña. La fortaleza sindical y parlamentaria del laborismo (ésta mucho me-

11 The Morning Post, 28-VII. Minuta de Eden, 31-VII. FO 371/20525 W7492. Minuta de G. Jebb, 25-XI-1936. FO $371 / 20570$ W15925. 
nor), unida a la creciente simpatía popular e intelectual por la Repúbilica, constituian límites infranqueables para la política exterior del gabinete, recientemente demostrados durante el conflicto italo-abisinio. Además, la preservación de un alto grado de consenso socio-político era objetivo y requisito del programa gubernamental de recuperación económica y apaciguamiento europeo. Todo ello motivó la prudencia observada en público por las autoridades y, en particular, impidió una demostración de simpatía y apoyo a los rebeldes como la que hubiera supuesto la adopción inmediata de una política de neutralidad oficial. En este sentido, la neutralidad tácita se presentaba como el único expediente disponible, cuya aplicación era solidaria de un supuesto de orden temporal: la expectativa de que la guerra seria breve, dado que las inexpertas y mal abastecidas milicias obreras no podrían contener el avance de un Ejército regular, experimentado y pronto abastecido por dos potencias militares de Europa. Dicho supuesto permitía considerar al neutralismo inconfeso como un refugio provisional, a la espera de que el curso de las hostilidades alcanzase un estadio (por ejemplo, la conquista rebelde de Madrid) que justificase políticamente su conversión en una neutralidad pública.

La estrategia británica esbozada quedó muy pronto amparada por el Acuerdo de No Intervención, cuyo origen estaba en la propuesta de embargo de armas colectivo hecha el 1 de agosto por Francia a todos los gobiernos europeos. En la intención francesa, se trataba probablemente de una fórmula para detener la ayuda exterior a los rebeldes ante su incapacidad propia para auxiliar a la República. Los gobernantes británicos la acogieron como el instrumento idóneo para ejecutar su política y salvaguardar los objetivos diplomáticos establecidos entonces por el Foreign Office. A saber: confinar la guerra en España, refrenando la intervención del aliado francés, evitando el alineamiento con la URSS y eludiendo el enfrentamiento con Italia y Alemania por su apoyo a los rebeldes ${ }^{12}$. De hecho, el Acuerdo firmado a fines de agosto, junto con el Comité de supervisión establecido en Londres, pasaron a constituir el dispositivo óptimo y quizá único para garantizar el cumplimiento de esos objetivos. Además, permitió mantener el embargo tácito británico de modo público y respetable, aplacando las críticas laboristas y ofreciendo al gobierno francés un escudo contra la presión prorrepublicana de sus bases sociales. Por consiguiente, para Londres la política multilateral de No Intervención contenía ab initio el germen de la impostura, en cuanto que su fin

\footnotetext{
${ }^{12}$ Memorándum de Sargent (subsecretario adjunto responsable del Departamento de Europa central); minutas de Mounsey (idem, Dpto. de Europa occidental) y Eden, 12, 13 y 15VIII-1936. FO $371 / 20534$ W9331.
} 
real no era el declarado (evitar la intervención exterior) sino la salvaguardia de los objetivos citados con su mera existencia y apariencia de operatividad. Es decir, era el recurso ideal para ejecutar una política definida confidencialmente por Winston Churchill en los siguientes términos:

Considero que lo más importante es hacer que Blum (el premier francés) permanezca con nosotros estrictamente neutral, incluso si Alemania e Italia continúan ayudando a los rebeldes y Rusia envía dinero al gobierno ${ }^{13}$.

Así pues, la No Intervención asumía una función dilatoria crucial en la política británica: cubria con puro bizantinismo diplomático el lapso temporal hasta la conquista insurgente de Madrid, hito clave que justificaría la adopción de una política oficial de neutralidad. Esta función dilatoria quedó demostrada desde finales de agosto, cuando el gabinete británico aceptó tácitamente y sin respuesta conminatoria la continuidad de la ayuda solapada italo-germana a Franco. Muy poco después, con motivo de la decisiva actuación italiana en Mallorca, Londres reiteró esa permisividad siempre que no se franqueasen los umbrales que para entonces habian fijado los estrategas militares británicos: 1. el respeto italiano al statu quo territorial español; y 2. la garantía de que el futuro gobierno español preservaría la benevolencia hacia Gibraltar y, en una posible guerra europea, «seria favorable, o en el peor de los casos, estrictamente neutral» hacia los intereses británicos ${ }^{14}$. Las actas del Comité de Defensa Imperial recogen esta disposición tolerante de modo inequívoco:

Sir Robert Vansittart afirmó que los italianos estaban desempeñando un papel considerable en Mallorca, pero habian dado las garantias más explicitas al Foreign Office de que no tenian intenciones ulteriores. ...En tanto el general Franco continuase con sus victorias, él pensaba que la intervención italiana era improbable ${ }^{15}$.

A tenor de esta declaración se aprecia claramente un aspecto esencial y poco resaltaro de la política británica ante la guerra española: era una

${ }^{13}$ Carta de Churchill a Eden, 7-V/II-1936. FO 954/27 (Archivo del FO, serie de correspondencia particular de Eden, legajo 27).

${ }^{14}$ Informe de los Jefes de Estado Mayor: «Mediterráneo occidental: situación originada por la guerra civil española", 24-VIIl-1936. Archivo del Gabinete, serie 24 (Cabinet Papers \& Memoranda), legajo 264. CAB 24/264. También impreso en Documents on British Foreign Policy, 2nd Series, vol. XVIl (London, HMSO, 1979), n. ${ }^{\circ}$ 26. En adelante: DBFP, vol. y n. .

${ }^{15}$ Acta, 8-X-1936. Archivo del Gabinete, serie 2 (Minutes of the Committee of Imperial Defence), legajo 6. CAB 2/6. EI CID era el organismo de coordinación de las politicas de defensa y exterior del Reino Unido. Presidido por el primer ministro, lo componían los ministros responsables de esos departamentos y los jefes de Estado Mayor. 
versión específica, si se quiere periférica, de la política general de apaciguamiento europeo. De hecho, la No Intervención británica se conformaría sistemáticamente a los parámetros establecidos por dicha política. En consecuencia, la actuación y presidencia británica en el Comité de supervisión fue un ejercicio continuo de dilaciones y evasivas a la espera de la conquista de Madrid, contingencia que los informes del servicio secreto pronosticaban como segura a corto plazo ${ }^{16}$. Paralelamente, Londres procuró no entorpecer en absoluto las operaciones militares insurgentes y adoptar todas las medidas favorables que fuesen compatibles con la imparcialidad oficial. Por ejemplo, reteniendo al embajador en Hendaya para que actuase como enlace con Burgos, negándose a admitir el bloqueo naval republicano, desalentando operaciones financieras republicanas en bancos británicos y congelando el uso de los fondos generados por la exportación española al Reino Unido. Todo ello bajo la convicción de que el peligro de hostilidad insurgente hacia el Reino Unido estaba mitigado por la clara hegemonia política de los militares y por los resortes previstos por la diplomacia de la libra para la postguerra. El especialista en asuntos españoles del Foreign Office recogió ambas razones en una minuta muy expresiva de octubre de 1936:

Nuestras posibilidades de recuperar la influencia en España durante esta fase (postbélica) son considerables debido a que la revolución española, a diferencia de las revoluciones fascista y nazi, habrá sido ganada esencialmente por los militares, que tienden por tradición hacia el Reino Unido y Francia más que hacia Alemania e Italia. Nuestras posibilidades se incrementarán y facilitarán si nosotros: 1. Adoptamos cuanto antes medidas para demostrar nuestra disposición amistosa hacia el general Franco y su gobierno; 2 . Somos capaces de ser útiles al gobierno español en el campo económico y financiero... Por consiguiente, es un interés británico que surja una dictadura militar liberal más que una dictadura fascista: 1. para contrarrestar la influencia italiana y alemana; 2. para estabilizar la situación interna ${ }^{17}$.

De hecho, hasta octubre de 1930, la estrategia política británica tuvo un éxito notable en el plano diplomático y bilateral anglo-insurgente. Pero

\footnotetext{
${ }^{16}$ El 10 de agosto, dicho servicio había comunicado que la guerra «estaba convirtiéndose en una lucha de rebeldes contra chusma» $y$ «los insurgentes están en mejor posición que el gobierno si éste es incapaz de obtener suministros del exterior». El 14 informaba que, «por consiguiente, una resistencia prolongada (en Madrid) es improbable». Archivo del Ministerio de Guerra (War Office), serie 106 (Directorate of Military Operations \& Intelligence), legajo 1576. Wo 106/1576.

${ }_{17}$ Minuta de Montagu-Pollock, 9-X-1936. Fo 371/20540 W12454. Sobre esas medidas circunstanciales de apoyo a los rebeldes véase Moradiellos, E., op. cit., págs. 261-303.
} 
a partir de entonces, la creciente denuncia laborista de la farsa de No Intervención, junto con la decisión soviética de enviar armas directamente a la República, introdujeron modificaciones transcendentales en el ámbito interno británico e internacional. Sobre todo, la intervención soviética tendría un efecto devastador porque posibilitaría la resistencia republicana en Madrid en noviembre de 1936, destruyendo asi la premisa fundamental sobre la que se habia vertebrado la politica británica. Además, esa conversión imprevista del conflicto en una guerra larga se produjo a la vez que Alemania e Italia intensificaban sustancialmente el apoyo militar y diplomático a Franco. Su reconocimiento de iure del gobierno nacionalista, unido al envio de auténticos cuerpos de ejército germano e italiano en noviembre y diciembre, superó por completo el nivel previo de ayuda limitada y encubierta y arruinó el confinamiento de la lucha que había logrado la No Intervención ${ }^{18}$. Todo ello obligó a los gobernantes británicos a reexaminar la situación y practicar reajustes notables en su política española.

El reajuste en el orden bilateral fue bastante rápido. La acción italogermana hacía imposible políticamente conceder la beligerancia y reconocer de facto al gobierno de Franco. Sin embargo, para no obstaculizar el propósito franquista de interceptar los suministros soviéticos con un bloqueo naval, el Foreign Office ideó un sucedáneo transitorio que no implicaba la concesión de los derechos de beligerancia maritimos: el 3 de diciembre una ley aprobada urgentemente prohibió el transporte de armas a España en mercantes británicos desde cualquier origen, encomendando a la Royal Navy la vigilancia de un embargo que sólo afectaba a la República (ya que parte del material soviético era transportado en barcos británicos) ${ }^{19}$. Al día siguiente, 4 de diciembre, después de tres semanas de negociaciones secretas en Burgos, se firmaba un Acuerdo Informal que regulaba las relaciones económicas entre Gran Bretaña y la España insurgente. Con él, se establecieron las bases que posibilitarían una recuperación inmediata del comercio bilateral, permitiendo así competir con la creciente actividad germano-italiana y garantizando el funcionamiento futuro de la diplomacia de la libra. Baste decir que al cabo de

${ }^{18}$ Sobre estos cambios véanse: NAYLOR, J. F., Labour's International Policy: The Labour Party in the 1930s (London 1969). BuCHanan, T., The Spanish Civil War and the British Labour Movement (Cambridge 1991). CATTELL, D., Soviet Diplomacy and the Spanish Civil War (Berkeley 1957). HASLAM, J., The Soviet Union and the Struggle for Collective Security in Europe (London 1984). WhEALEY, R., Hitler and Spain (Lexington 1989). Coverdale, J., La intervención fascista en la guerra civil española (Madrid 1979).

19 Acta de reunión ministerial, 22-X1-1936. CAB 24/265. Memorándum sobre la Royal Navy y la guerra española, marzo 1938. Archivo del Almirantazgo (Admiralty Records), serie 116, legajo 3677. ADM 116/3677. 
un año las exportaciones británicas a zona insurgente sumaban el 75 por 100 de todas las destinadas a España ${ }^{20}$.

El reajuste de la política británica en su dimensión internacional fue más lento y polémico. En diciembre, Eden intentó varias veces que sus colegas reconocieran la necesidad de modificar la conducta previa a tono con la nueva fase de guerra larga y masiva intervención italo-germana. A su juicio, compartido por sus asesores más cercanos en el Foreign Office, los riesgos políticos y estratégicos planteados por esa intervención, sobre todo en Mallorca, se habian convertido en el factor decisivo del problema español, dadas las tendencias expansionistas y potencialmente antibritánicas del nuevo Eje formado por ambas dictaduras. Sin embargo, los ministros desestimaron su interpretación, argumentando que «abstenerse de actuar era importante desde el punto de vista de las negociaciones con Italia» y era suficiente con una reafirmación de la promesa italiana de respeto al statu quo mediterráneo ${ }^{21}$. En consecuencia, como primer paso para restablecer la entente anglo-italiana, el Foreign Office siguió negociando con Roma una declaración conjunta de respeto a los intereses recíprocos mediterráneos: el llamado Acuerdo entre Caballeros hecho público el 2 de enero de $1937^{22}$. No obstante dicho acuerdo, el continuo envio masivo de tropas italianas a España motivó otra tentativa de revisión política por parte de Eden. El 8 de enero de 1937 propuso al gabinete la adopción de medidas resolutivas y conminatorias (por ejemplo, un bloqueo naval de las costas españolas) para mostrar a Hitler y Mussolini la voluntad británica de frenar su actividad en España. En sus palabras:

La guerra civil ha dejado de ser un asunto interno español y se ha convertido en un campo de batalla internacional. El carácter del futuro gobierno de España es ahora menos importante para la paz de Europa que el hecho de que los dictadores no obtengan la victoria en ese país. ...a menos que exijamos un alto en España, tendremos problemas este año en uno u otro de los focos de peligro señalados (Memel, Danzig o

\footnotetext{
20 Memorándum: The Anglo-Spanish Clearing, 8-Vl-1937. Archivo del Ministerio de Comercio (Board of Trade Records), serie 11 (Commercial Relations \& Treaties Department), legajo 833. BT 11/833. Minuta para Eden, 8-X1-1937. FO 371/21384 W20546. Despacho del embajador (Hendaya), 7-XII-1936. Archivo del F.O., serie 425 (Confidential Prints. Western Europe), legajo 413. FO 425/413.

${ }^{21}$ Memorándum de Eden: Spain. The Balearic Islands, 14-XII. FO 371/20588 W18182. Acta del gabinete, 16-XII-1936. CAB 23/86. Eden reconoció la confianza que se habia tenido en el supuesto de la guerra breve: «Si el general Franco hubiese ganado la guerra con anterioridad, no habrian surgido grandes dificultades como la aventura de Mallorca».

${ }^{22}$ DBFP, XVII, n. ${ }^{\circ}$ 530. Coverdale, J., op. cit. , págs. 188-189.
} 
Checoslovaquia). Consecuentemente, ser firmes en España es ganar tiempo y ganar tiempo es lo que queremos. En esta ocasión no podemos ganar tiempo con dilaciones... Considero imperativo que no escatimemos ningún esfuerzo para detener la intervención en España.

Sin embargo, el gabinete volvió a rechazar la propuesta de Eden por considerarla contradictoria con el objetivo de acercamiento a Italia y porque conllevaba la revisión incipiente de otra premisa básica de la política de apaciguamiento: evitar el alineamiento con la URSS. A este respecto, Sir Samuel Hoare, Primer Lord del Almirantazgo, rechazó los temores a un triunfo franquista con el argumento de que «había otros, incluyendo quizá algunos miembros del gabinete, que querian a toda costa que los soviéticos no triunfasen en España» ${ }^{23}$.

En esencia, el desacuerdo sobre el peligro presente en España era resultado de la divergencia creciente sobre la viabilidad de la política de acercamiento a Italia y el modo de aplicarla. Eden consideraba que había de practicarse desde una posición de fuerza, a fin de no aumentar el prestigio de Mussolini y su tentación de aliarse con Berlín para obtener la hegemonía mediterránea. Por el contrario, sus colegas estimaban que el apaciguamiento de Italia era factible dada su debilidad económica y el conflicto entre sus ambiciones y las alemanas en Austria y los Balcanes. En este dilema, la guerra española era o bien un campo de prueba de la bona fides italiana o bien un obstáculo marginable que no debía interferir en la política trazada. En todo caso, la divergencia fue subsanada provisionalmente el 9 de enero de 1937, cuando el gabinete aceptó un programa de acción diplomática elaborado por Eden que representaba un compromiso entre sus frustradas propuestas y la inhibición a ultranza. El Foreign Office intentaria detener la escalada intervencionista mediante presión directa sobre Roma y Berlín y a través del Comité de No Intervención, al que se propondría prohibir la salida de voluntarios extranjeros hacia España y adoptar urgentemente un plan de control realizable de las fronteras y costas españolas. Así pues, el reajuste político británico concluía con la decisión de intentar hacer efectiva la No Intervención, respetando los parámetros generales de la política de apaciguamiento. El carácter inviolable de estos parámetros fue reforzado por el siguiente juicio estratégico emitido por los Jefes de Estado Mayor: "en ninguna circunstancia deberiamos luchar para que los italianos no ocupen Baleares,

${ }^{23}$ Acta del Comité de Política Exterior, 8-1-1937. Archivo del Gabinete, serie 27 (Committee on Foreign Policy), legajo 628. CAB 27/628. Dicho comité constituia un mini-gabinete compuesto por los principales ministros, encargado de preparar los asuntos de politica exterior a decidir por el gabinete en pleno. 
puesto que no era un interés vital para nosotros como lo era para los franceses" 24 .

A pesar del estrecho margen de maniobra disponible, los esfuerzos de la diplomacia británica, bajo el impulso de Eden, lograron una pausa en la ofensiva intervencionista italo-germana. Ni Hitler ni Mussolini deseaban forzar más de lo necesario la permisividad británica y tampoco estaban dispuestos a que su ayuda a Franco precipitara una guerra prematura. En consecuencia, abandonaron el obstruccionismo y aceptaron las propuestas para convertir la No Intervención en una realidad práctica. A mediados de febrero de 1937, el Comité prohibió la salida de voluntarios extranjeros con destino a España y aprobó un plan de control que entraría en vigor dos meses después ${ }^{25}$. Desde entonces, las fronteras francesa y portuguesa con España quedaron vigiladas por observadores internacionales que también embarcaban en los mercantes europeos dirigidos a puertos españoles. Completando el control, las flotas británica y francesa se encargaron de patrullar la costa insurgente mientras las flotas italiana y germana hacían lo propio en la costa republicana.

La distensión lograda así en el ámbito internacional posibilitó que Eden intentase de nuevo un pronunciamiento firme del gabinete en otro contencioso pendiente: la requisa insurgente de piritas propiedad de compañías británicas y su exportación a Alemania e Italia para compensar la ayuda recibida. A primeros de marzo, basándose en la necesidad de garantizar el suministro de ese mineral estratégico y la resistencia insurgente a un compromiso, Eden propuso que la Royal Navy interceptase los barcos cargados con piritas requisadas. Sin embargo, el gabinete desestimó esa demostración de fuerza naval ante Franco al igual que la había rechazado ante Italia y Alemania. El ministro de Hacienda, Neville Chamberlain, que sucedería a Baldwin como primer ministro dos meses después, encabezó la oposición a Eden con una defensa enérgica de la conveniencia de esperar a la postguerra para poner en vigor la diplomacia de la libra:

Habia que recordar que no estábamos tratando sólo con los insurgentes españoles sino también, tras de ellos, con los alemanes e italia-

\footnotetext{
${ }^{24}$ Acta, 9-1-1937. CAB 27/628. Acta de la Junta de Jefes de Estado Mayor, 11-I-1937. Archivo del Gabinete, serie 53 (Minutes of the Chief of Staff Sub-Committee), legajo 6. CAB $53 / 6$.

${ }^{25}$ Sobre la cautela italo-germana véase: Documents on German Foreign Policy, Series D, vol. III (Germany and the Spanish Civil War) (London 1951), n. ${ }^{\circ} 197,200$ y 215. En adelante: DGFP y n. ${ }^{\circ}$ Ciano's Diplomatic Papers (London 1948), págs. 85-87. Sesiones del Comité de No Intervención, 16-II y 8-1II-1937. Archivo del Comité de No Intervención, legajos 1 y 27. FO $849 / 27$
} 
nos. El general Franco no era un agente libre. Sin duda que esperaba triunfar, pero dificilmente sin la ayuda italiana y alemana... Por tanto, insistir en la propuesta no sólo era inútil sino que llevaria a una situación muy grave con Alemania e italia. Sin embargo, suponiendo que Franco hubiese ganado la guerra civil, la situación sería muy diferente porque entonces se encontraría buscando la ayuda de otros paises además de la de Alemania e Italia. Ese sería el momento de ejercer fuerte presión sobre él. ...ése sería el momento para actuar ${ }^{26}$.

La derrota de Eden en este asunto fue completa, aunque el gabinete le autorizó a presentar una protesta enérgica en Burgos y, de ese modo, obtuvo la garantía de que el suministro de piritas a Gran Bretaña no se interrumpiría por las requisas (como en efecto así fue). Sin embargo, un mes después de esa derrota, en abril de 1937, Eden consiguió la aprobación del gabinete para una demostración de fuerza en el más puro estilo de la diplomacia de la cañonera. Su origen estaba en el bloqueo naval de Bilbao impuesto por Franco, complemento indispensable de su nueva estrategia de eliminación gradual del frente norte una vez estancada la ofensiva sobre Madrid. Debido a la falta de derechos de beligerancia marítimos, el bloqueo sólo podía ejercerse dentro de las tres millas jurisdiccionales españolas; un límite estrecho para capturar los mercantes que intentasen burlar el bloqueo y fácil de vigilar por la defensa costera republicana. En consecuencia, Franco trató de forzar el reconocimiento de beligerancia mediante el ejercicio del bloqueo en aguas internacionales, negándose a admitir una oferta británica para llegar a un compromiso mutuamente aceptable. Este hecho, unido a la presión de la opinión pública, obligó al gabinete a conceder protección naval a los mercantes británicos hasta las tres millas. La flota insurgente hubo de claudicar así ante la enorme superioridad de la Royal Navy y cesar sus actividades en alta mar, al menos respecto al tráfico británico. En privado, Eden comentaria: «Este gobierno sería más reaccionario (en su política española) si yo no estuviera en él» ${ }^{27}$.

La politica de firmeza alentada por Eden en los planos diplomático y bilateral tenía como corolario la creación de las condiciones propicias para un armisticio y mediación en el conflicto. A su juicio, compartido por

${ }^{26}$ Memorándum de Eden; Nota de Hoare; 1 y 3-III. CAB 24/268. Acta del gabinete, 3-III1937. CAB 23/87. Cfr. SMYTH, D., «The Moor and the Money-lender: Politics and Profits in Anglo-German Relations with Francoist Spain, 1936-1940», en M.L. Recker (ed.), From Competion to Rivalry (Stuttgart 1986), págs. 143-174.

27 Actas del gabinete, 7, 11, 14, 19 y 21-IV-1937. CAB 23/88. CABLE, J., The Royal Navy and the siege of Bilbao (Cambridge 1979). The Diplomatic Diaries of Oliver Harvey, 19371940 (London 1970), pág. 40. Harvey era secretario particular de Eden en el Foreign Office. 
el gabinete, ésa sería la solución ideal para el problema español y la más ventajosa para los intereses británicos. Por eso, en abril y mayo de 1937, el Foreign Office sondeó la disposición de las potencias europeas al respecto, a la par que defendía el libre tráfico en alta mar y presentaba al Comité de No Intervención un plan para la evacuación de España de los combatientes extranjeros (denominados oficialmente «voluntarios» para equiparar las tropas fascistas con los brigadistas internacionales) ${ }^{28}$. Sin embargo, las previsiones de Eden se vinieron abajo en el verano de 1937, con la retirada germano-italiana de la patrulla naval y la consiguiente suspensión del control de las costas y fronteras. La iniciativa italo-germana, un verdadero ejercicio de tanteo sobre la permisividad británica, pretendía interrumpir el debate sobre la evacuación de «voluntarios» y forzar la concesión de la beligerancia a Franco en sustitución de la patrulla naval ${ }^{29}$.

La reacción británica ante el colapso virtual de la No Intervención efectiva fue muy prudente, bajo la premisa de que «nuestro objetivo primordial es evitar el deterioro de nuestras relaciones con Alemania e Italia». El gabinete decidió mantener vigente a toda costa el Comité de No Intervención «a fin de proporcionar la apariencia de acuerdo internacional». Para ello, el Foreign Office presentó al Comité el llamado Plan Británico del 15 de julio, que contemplaba la concesión de la beligerancia a los bandos españoles cuando hubiese comenzado la evacuación de voluntarios. Esa propuesta de compromiso fue aceptada como «base de discusión" por Hitler y Mussolini, conscientes de que significaba el retorno a la situación bizantina anterior a enero de 1937 y el fin práctico del control de No Intervención ${ }^{30}$.

La retirada británica en el frente diplomático fue seguida de un agravamiento de la tensión internacional en agosto, a causa de la ayuda italiana al bloqueo insurgente. Con objeto de cortar los envíos soviéticos, submarinos italianos comenzaron a operar en todo el Mediterráneo contra el tráfico destinado a puertos republicanos. En el plazo de un mes, al menos once mercantes y un destructor británicos fueron atacados en alta mar por submarinos supuestamente «piratas». En esas circunstancias, Eden convenció al gabinete de que la acción italiana excedia los márgenes de tolerancia admisibles y que el prestigio e interés británicos exigían

${ }^{28}$ Actas del gabinete, 28-IV y 5-V-1937. CAB 23/88. DBFP, XVIII, $n .^{\circ} 482$. Sesión del Comité, 26-V-1937. FO 849/1.

${ }^{29}$ Coverdale, J., op. cit., págs. 274-276. DGFP, n. ${ }^{\circ} 360,366$ y 371. WeinBerg, G., The Foreign Policy of Hitler's Germany (Chicago 1980), vol. Il, págs. 99-102 y capitulo V.

${ }_{30}$ Actas del gabinete, 30-VI y 7-VII-1937. CAB 23/88. Sesión del Comité, 16-VII-1937. FO 849/1. DGFP, n. ${ }^{\circ} 375,376$ y 396. 
actuar en defensa del libre tráfico en el Mediterráneo. El resultado fue la Conferencia de Nyon de septiembre de 1937, en la que todos los países ribereños, con la ausencia italiana, decidieron encomendar a la flota anglo-francesa la patrulla del Mediterráneo para terminar con los ataques piratas ${ }^{31}$. Las resoluciones de Nyon mostraron claramente a Italia los limites de la permisividad británica y pusieron fin a las operaciones navales fuera del teatro español.

Sin embargo, Nyon fue la última vez que el gabinete secundó la política de firmeza de Eden en el asunto español. A partir de entonces, la necesidad de reajustar esa politica ante el fracaso de la No Intervención efectiva fue agravando la divergencia latente desde enero tanto en el gabinete como en el propio Foreign Office.

Durante los meses finales de 1937, Eden reiteró su tesis de que la intervención en España constituía el campo de prueba de la bona fides italiana respecto a Gran Bretaña. Sobre todo, en vista de la cristalización del Eje con la visita de Mussolini a Berlín y del proceso de fascistización que estaba registrándose en la España insurgente, con sus crecientes alusiones a la recuperación de Gibraltar ${ }^{32}$. Por ello, la apertura de negociaciones para un acuerdo anglo-italiano debia condicionarse, como mínimo, a una retirada de las tropas italianas de Baleares y al apoyo fascista al plan de evacuación de voluntarios debatido en el Comité de No Intervención. Mientras tanto, el interés británico exigía la prolongación de la guerra y abstenerse de presionar al gobierno francés para que cerrase su frontera al contrabando de armas republicano. El 29 de septiembre declaró en el gabinete:

Es evidente que no nos interesa que el final de la guerra llegue con rapidez, puesto que una victoria total y pronta de Franco incrementaría enormemente el prestigio de Italia ... Un triunfo rápido en España haría que Alemania e Italia se volviesen intratables a efectos de negociación y quizá peligrosos en otras direcciones... Debemos confiar en que los chinos en Asia oriental y el gobierno español en el Mediterráneo puedan

${ }^{31}$ Reunión de ministros, 17-VIII y 2-IX; Acuerdo de Nyon, 11-IX-1937. DBFP, XIX, n. ${ }^{\circ} 94$, 114 y 156. Memorándum del Almirantazgo, marzo 1938. ADM 116/3677. ALPERT, M., La guerra civil española en el mar (Madrid 1987), págs. 288-289.

32 Weinberg, G., op. cit., págs.274-283. El embajador y primer secretario en Hendaya remitieron dos despachos (23-1X y 13-X-1937) advirtiendo que la prolongación de la guerra estaba generando un nacionalismo totalitario en la España franquista, inquietante para Gibraltar. El segundo subrayaba que parecia que «España era sólo otra etapa italiana en la puesta en práctica de la política de Mare Nostrum comenzada con el ataque a Abisinia». Ambos fueron impresos y el segundo remitido a los ministros por orden de Eden. FO 425/ 414. 
ofrecer una resistencia duradera; y aunque nosotros no estemos dispuestos a proporcionarles ninguna ayuda efectiva, desde luego que no debemos debilitarles... Tal política de no hacer nada que acelere la victoria nacionalista no se contradice con el propósito de eliminar las causas de fricción entre nosotros e Italia sobre la base del respeto mutuo.

Sin embargo, sus tesis fueron impugnadas por los restantes ministros. En el plano estratégico, los jefes de Estado Mayor reiteraron la prioridad de una entente mediterránea con Italia y dictaminaron que «no hay razones fuertes estratégicas para exigir la evacuación de Baleares del personal italiano» y «sería más seguro limitarse a pedir una reafirmación (del respeto a la integridad española)». En el orden político, Chamberlain subrayó la urgencia de iniciar cuanto antes las conversaciones con Italia porque había posibilidad de separarla de Alemania y «ésto era tan importante para la paz que merecía la pena correr algunos riesgos». El dilema planteado se solucionó al aprobar el gabinete un curso político intermedio, definido por Lord Halifax, Lord Presidente del Consejo, del siguiente modo:

Nuestro primer esfuerzo sería intentar que Mussolini retirase los voluntarios italianos. Era improbable que pudiese acceder a ello. Entonces deberiamos inducirle a que no enviase más voluntarios y a que reafirmase las garantías que ya había dado respecto a sus objetivos últimos. En síntesis, deberiamos intentar lograr todo lo posible en el segundo punto, con vistas a tranquilizar a Francia ${ }^{33}$.

Eden, a pesar de mantener su reserva, asumió la decisión ministerial y procuró ejecutarla en los meses sucesivos. La eliminación del frente norte fue aprovechada para negociar un intercambio de agentes diplomáticos con Burgos en noviembre de 1937, una medida que supuso el reconocimiento del gobierno franquista como gobierno de facto en España. El propósito era contrarrestar la influencia del Eje en Burgos y preparar los resortes previstos por la diplomacia de la libra para la postguerra, aunque públicamente se justificó «con argumentos comerciales más que políticos en vista de las críticas de la izquierda en Gran Bretaña» ${ }^{34}$.

Paralelamente, el Foreign Office propuso a Roma conversaciones tripartitas con Francia para solucionar el problema de los voluntarios y «ha-

\footnotetext{
${ }^{33}$ Nota de Eden para leer en el gabinete, 2-IX. FO 371/21401 W17119. Acta del gabinete, 29-IX. CAB 23/89. Informe de los Jefes de Estado Mayor, 29-IX-1937. DBFP, XIX, n. 209.

${ }^{34}$ Memorandos sobre relaciones con Franco, 17-VIII y 5-XI-1937. FO $371 / 21299$ W15799 y FO 371/21401 W20397. Minuta sobre aspectos juridicos, 23-XI-1937. FO 371/21402 W20727. La frase citada es de Chamberlain (24-XI-1938). FO 371/22657 W16097.
} 
cer realmente efectiva la política de No Intervención». Como el gabinete había anticipado, la respuesta italiana (9 octubre) fue negativa, remitiendo el asunto al Comité y anunciando que no participaría en conversaciones en las que no estuviera presente Alemania. Ante ese fracaso, el gobierno francés solicitó la conformidad británica para abrir su frontera al paso de armas con destino a la República. Pero, a pesar del esfuerzo de Eden, el gabinete resolvió negar esa conformidad expresamente y aceptar la propuesta italiana de seguir las deliberaciones en el Comité. Chamberlain defendió esta politica con el siguiente argumento:

Puede que el momento actual sea de importancia crucial para Europa y bien pudiera ser que el futuro del Mediterráneo dependiese de cómo se resolviera. Posiblemente, nosotros teníamos la clave en el asunto porque el gobierno francés, aunque ahora estuviese bajo la influencia del pánico, sin duda atribuía gran importancia al mantenimiento de buenas relaciones con nosotros. Por tanto, el gobierno francés haría bastantes concesiones a fin de acomodarse a nuestro punto de vista ${ }^{35}$.

Y, efectivamente, dada la oposición británica, Paris decidió mantener cerrada su frontera y seguir debatiendo el asunto en el Comité. Por su parte, Roma trató de amortiguar su negativa con una actitud menos obstruccionista en el Comité, cuyo resultado fue la aprobación por el mismo de un complicado plan de evacuación de voluntarios en noviembre de $1937^{36}$. Aun así, la divergencia entre Eden y sus colegas sobre el perfil de la política española no dejó de incrementarse hasta llegar a su punto culminante en febrero de 1938.

A mediados de ese mes, bajo la sombra de la inminente anexión nazi de Austria, Mussolini solicitó a Londres la apertura urgente de negociaciones para un acuerdo bilateral que incluyese el reconocimiento británico del imperio italiano en Abisinia. Eden, sospechando que Roma deseaba compensar con un éxito diplomático su abandono de la independencia austriaca, propuso al gabinete que se condicionara esa apertura a «una indicación de buena fe italiana» en España. A su juicio, la colaboración en la retirada de voluntarios seria la prueba de que Roma deseaba un acuerdo leal y no perseguía la instalación de un régimen español favorable a sus proyectos de hegemonia mediterránea y aliado en caso de guerra. Por el contrario, Chamberlain, entendiendo que Mussolini trataba de recuperar su política de equidistancia entre Berlín y Londres,

${ }^{35}$ Actas del gabinete, 13 y 20-X-1937. CAB 23/89. Telegramas del embajador en París, 25-X-1937. FO 371/21347 W19609 y W19656.

${ }_{36}$ Sesión del Comité, 4-XI-1937. FO 849/1. 
propuso la apertura inmediata de negociaciones y seguir marginando el asunto español como hasta entonces. Tanto Eden como Chamberlain compartían la premisa de que «no es posible ningún apaciguamiento duradero en el Mediterráneo hasta que la úlcera española sea cicatrizada». Sin embargo, mientras Eden pretendía cicatrizarla con la retirada italiana y la mediación, Chamberlain estaba dispuesto a condonar la intervención italiana y asumir la consecuente terminación de la guerra con la victoria de Franco. El resto del gabinete secundó al primer ministro y, por tanto, Eden dimitió el 20 de febrero de 1938, siendo sustituido por Lord Halifax como secretario del Foreign Office. Ello no obstante, el impacto de la dimisión de Eden en la opinión pública y el Parlamento forzó una concesión importante de Chamberlain: el posible acuerdo anglo-italiano habria de incluir «una solución de la cuestión española»"

Asi pues, el Foreign Office inició las conversaciones para el acuerdo bajo la condición de que éste incluiría una "solución de la cuestión española». Chamberlain rehusó definir exactamente el significado de esa condición, sin embargo el secretario privado de Lord Halifax anotó en su diario que significaba: «cuando Franco haya vencido". De hecho, en marzo y abril de 1938, el gabinete británico pensó que la victoriosa ofensiva franquista en Aragón estaba a punto de eliminar por sí misma la cuestión española. En consecuencia, el 16 de abril se concluyó el Acuerdo AngloItaliano que, entre otras cosas, prescribia el reconocimiento del imperio abisinio y la renovación por Italia de la garantía de respeto a la integridad española y su promesa de retirar los voluntarios italianos «al término de la guerra civil». La entrada en vigor del Acuerdo, sin embargo, quedaba aplazada hasta que se hubiese alcanzado la condición impuesta por Londres: «una solución de la cuestión española» ${ }^{38}$.

${ }^{37}$ Con Eden dimitió Lord Cranborne, subsecretario parlamentario del FO. Vansittart, que compartía las tesis españolas de Eden, ya había sido promovido/relegado a Primer Consejero Diplomático. Memorándum del FO, 25-X-1937; Notas del diario de Chamberlain y Acta del gabinete, 19-1l-1938; Telegrama de Lord Halifax al embajador en Roma, 21-11-1938. DBFP, $\mathrm{XIX}, \mathrm{n} .{ }^{\circ} 269,568,573$ y apéndices I y II. Eden, A., The Eden Memoirs. Facing the Dictators (London 1962), págs. 579-592. Ciano's Diplomatic Papers, págs. 164-184.

${ }^{38}$ The Diplomatic Diaries of Oliver Harvey, pág.124. Lord Halifax informó al gabinete (16|1|-1938) que "las fuerzas del gobierno español estaban siendo completamente derrotadas». El 30 comunicó que "las conversaciones con el gobierno italiano van bien» y "estaremos en condiciones de aprovechar esta libertad de acción tan pronto como la situación en España lo permita». El 13 de abril reconoció que «el supuesto contemplado en el canje de notas era que la guerra española hubiera terminado». CAB 23/92 y 93 . Cfr. el editorial de The Times (9-VII-1938): "Al firmarse el Acuerdo en Roma, ambas partes tenian la impresión de que "la solución en España" era inminente y sería aportada por la victoria del general Franco"s. 
Desgraciadamente para el gobierno británico, el supuesto de la victoria de Franco contemplado en el Acuerdo resultó ser prematuro. El 16 de marzo de 1938, el nuevo y breve gobierno de Blum en Francia había abierto secretamente la frontera al paso de armas soviéticas que posibilitarían la resistencia republicana. Tras la caída de ese gobierno (8 de abril), el esfuerzo del Foreign Office se centró en lograr que el gobierno de Daladier cerrase la frontera al tráfico de armas. De hecho, tras la dimisión de Eden, la política británica ya no consistía en esperar más o menos impasiblemente la derrota militar republicana sino que implicaba acelerar en cuanto estuviera a su alcance esa solución, a fin de permitir la entrada en vigor del Acuerdo y el apaciguamiento de Italia. Bajo la convicción de que «la ayuda francesa está retrasando, nadie sabe por cuánto tiempo, cualquier solución posible en España», Londres ejerció una presión constante sobre el gobierno francés para que cerrase la frontera y dejase de prolongar la guerra ${ }^{39}$. A principios de junio de 1938 , aprovechando que la creciente crisis germano-checa incrementaba el valor de la alianza británica para Francia, el Foreign Office decidió forzar una decisión en París. El embajador británico comunicó al ministro francés de Asuntos Exteriores que su gobierno «no comprendía por qué el gobierno francés era incapaz de cortar el paso de armas en la frontera con Barcelona. Seria una gran desgracia que por este motivo decayese la simpatía con Francia en Gran Bretaña». Como resultado indudable de esta gestión, París cerró la frontera el 13 de junio, eliminando la vía esencial de suministros republicanos y dejando éstos al albur del bloqueo naval franquista. Ello no obstante, a fines del mismo mes, el embajador reiteró su advertencia al propio Daladier para evitar la reapertura de la frontera ante el recrudecimiento de la intervención italiana. En esa ocasión, transmitió «la importancia vital que el gobierno británico atribuye al cierre permanente de la frontera pirenaica». Y añadió que era necesario «mantener esa frontera infernal cerrada" y evitar que los rusos siguieran enviando material a la República porque «si lo consiguen la guerra se prolongaría por muchos meses" ${ }^{40}$.

39 Telegramas del embajador en Paris, 15, 16 y 17-111-1938. FO 371/22659 y 22639 W3363, W3424, W3484 y W3491. Minutas de Mounsey y Sir Alexander Cadogan (Subsecretario Permanente del F.O.), 8-IV-1938. FO 371/22642 W4718. Acta de las conversaciones anglo-francesas, 28 y 29-IV-1938. FO $371 / 21591$ C3687.

40 Telegramas del F.O. al embajador en Paris y viceversa, 7 y $8-\mathrm{VI}-1938$. FO $371 / 22659$ W7332 y W7352. Carta del embajador a Lord Halifax, 29-VI-1938. FO 800/323. Archivo del F.O., serie 800 (Private Collections), legajo conteniendo la correspondencia privada de Lord Halifax. 
Así pues, como apuntó en su diario el secretario de Lord Halifax: «El gobierno está rezando por la victoria de Franco" ${ }^{41}$. Por ello, se abstuvo de responder enérgicamente a los ataques aéreos franquistas contra el tráfico mercante con la República, contentándose con protestas diplomáticas y pedir a Roma que moderase el número de ataques y su incidencia sobre buques británicos. Igualmente, el abandono de toda esperanza de hacer efectiva la No Intervención se demostró en el hecho de que el Comité sólo se reuniera una vez durante 1938: en julio y únicamente para aprobar un complejo plan de evacuación de voluntarios absolutamente impracticable. Naturalmente, esta política seguía teniendo como base la confianza en la diplomacia de la libra para el futuro. Lord Halifax lo recordó al gabinete el 27 de julio:

Alemania e Italia habian hecho grandes cosas por España, pero después de la guerra lo que España necesitará será dinero y ésto sólo lo tenía el Reino Unido. Por tanto, ellos serían los únicos beneficiarios de la guerra ${ }^{42}$.

La convicción del gabinete de que los riesgos implícitos en la victoria franquista no eran tan graves como Eden había predicho se vio aparentemente corroborada por la conducta de Franco durante la crisis de septiembre que desembocaría en el Acuerdo de Munich y el reparto de Checoslovaquia. Los estrategas británicos habían previsto que en caso de guerra la España de Franco sería favorable a Alemania y proporcionaría ayuda logística a su flota. Sin embargo, el 27 de septiembre, mientras Londres y París se aprestaban con reticencia a combatir si Hitler rechazaba su oferta de compromiso, Franco informó a ambos gobiernos que mantendría «una actitud de completa neutralidad» ${ }^{43}$. La solución de la crisis en Munich evitó que Franco tuviera que poner a prueba su intención y también evitó que Londres tuviese que comprobar la viabilidad de su propósito de mantener aislado el conflicto español aun en caso de guerra por Checoslovaquia. De todos modos, la conferencia de Munich y el papel

${ }^{41}$ The Diplomatic Diaries of Oliver Harvey, pág. 148.

${ }_{42}$ Acta del gabinete, 27-VII-1938. CAB 23/94. Halifax repetía la opinión del embajador alemán en París. Sobre la pasividad ante los bombardeos, véanse las actas del gabinete (29-VI y 6-VII). CAB 23/94. Nota de Lord Halifax para Chamberlain, 9-VI-1938. Archivo del Primer Ministro (Prime Minister's Office), serie 1 (Correspondence \& Papers), legajo 360. PREM 1/360. Sesión del Comité, 5-VII-1938. FO 849/1.

${ }_{43}$ Nota del ministro para la Coordinación de la Defensa: Apreciación de la situación en caso de guerra con Alemania, 14-IX-1938. CAB 24/278. Telegramas del agente británico en Burgos, 23, 27 y 28-IX-1938; minutas de Mounsey y Cadogan, 28-IX-1938. FO 371/22698 W13084, W12929, W13030 y W13118. 
de Mussolini en ella reforzaron enormemente la determinación británica de eliminar el obstáculo español que impedía la reconciliación con Italia.

A mediados de octubre, el Foreign Office dictaminó que la neutralidad de Franco «era una clara indicación de que no permitiria ser dominado por potencias extranjeras» y «eliminaba cualquier temor francés sobre su frontera sur». En esas condiciones, «El gobierno de Su Majestad debería separarse categóricamente de cualquier intento de solución de los asuntos internos españoles» y abandonar cualquier idea de mediación ${ }^{44}$. Atendiendo a estos principios, el 2 de noviembre de 1938 el gabinete anunció la entrada en vigor del Acuerdo anglo-italiano, argumentando que después de Munich era evidente que el conflicto español «había dejado de ser una amenaza para la paz de Europa» y, por tanto, ya se había cumplido la condición de hallar «una solución a la cuestión española». Lord Halifax reconoció implícitamente que ello significaba aceptar la victoria franquista al declarar en la Cámara de los Lores:

Desde el principio de las conversaciones entre el gobierno británico y el italiano, Mussolini siempre había dejado claro que, por razones de todos conocidas, tanto si las aprobábamos como si no, no estaba dispuesto a consentir la derrota del general Franco ${ }^{45}$.

Esta decisión del gabinete fue duramente criticada por la oposición laborista y por los conservadores más sensibles a la amenaza del Eje, entre ellos Eden, que atribuyó el deterioro de la situación internacional a la falta de firmeza británica en España. En enero de 1939, el éxito de la ofensiva franquista en Cataluña permitió que la tesis de Eden encontrase eco renovado en los círculos oficiales. Tres días antes de la caída de Barcelona, Sir Robert Vansittart y el ministro de Comercio presionaron fuertemente al gabinete para revisar su conducta. A juicio de ambos, el creciente expansionismo del Eje hacía muy peligrosa una rápida victoria de Franco y aconsejaba eliminar el veto a la ayuda francesa para posibilitar la resistencia republicana. Sin embargo, la mayoría del gabinete compartió la tesis de Chamberlain de que «cuanto primero terminase la guerra en España más oportunidades habia de mejorar las relaciones italo-francesas». Además, en el peor de los casos, la destrucción provocada por la lucha impediría que Franco "estuviese en posición de ser una molestia para nadie», mientras que «nuestra supremacia naval en el Medi-

${ }^{44}$ Memorándum de Mounsey, 21-X-1938. FO 371/22655 W14422.

${ }_{45}$ Parliamentary Debates. House of Lords, 3-XI-1938, col.1624. Acta del gabinete, 26-X1938. CAB 23/96. 
terráneo haria que Italia no pudiese hacer nada efectivo contra nosotros o contra Francia». En esas condiciones, el gabinete ratificó la política española seguida, con la salvaguardia de que, a fin de no excitar las críticas de la oposición, «debíamos evitar cualquier muestra de satisfacción ante la perspectiva de una victoria de Franco» ${ }^{46}$.

Tras la conquista de Cataluña, y siguiendo la política de pasividad expectante, el Foreign Office se dispuso a preparar el reconocimiento de iure del gobierno franquista. Sólo en un caso, a principios de febrero de 1939, se permitió una notable intervención diplomática en el conflicto. A petición de Franco, Londres autorizó que un buque británico llevase un emisario nacionalista a Menorca para proponer a los republicanos la rendición a cambio de ser evacuados a Francia en el mismo buque. La posición estratégica de la isla, junto con las garantías de Franco de que seria ocupada sin fuerzas italianas o alemanas, hicieron posible esta intervención británica en la rendición pacífica de Menorca ${ }^{47}$. Sin embargo, la medida no se repitió en las semanas siguientes, cuando el gobierno republicano solicitó la mediación británica para negociar con Franco una rendición que incluyese garantías contra represalias indiscriminadas y autorización para exilarse a los republicanos que lo desearan. Londres aceptó únicamente actuar como transmisor de la propuesta republicana, negándose a presionar a Franco para que la aceptara o a asumir ninguna responsabilidad sobre el cumplimiento de las garantías ${ }^{48}$. Finalmente, el 27 de febrero de 1939, el gabinete británico, a la par que el francés, reconoció formalmente al gobierno franquista. El desahucio de la República estaba consumado. Ni siquiera el golpe del coronel Casado modificó la negativa británica a actuar como mediador en las negociaciones de ren-

\footnotetext{
${ }^{46}$ Acta del Comité de Política Exterior, 23-1-1939. CAB 27/624. Dentro del Foreign Office hubo notable oposición a Vansittart, basándose en el peligro de una victoria republicana. El 7 de enero, un memorándum de O'Malley, aprobado por Mounsey y Sargent, expuso así la razón: «Considero un grave error suponer clue el gobierno Negrín continuaria con su moderación y disciplina una vez eliminada la inmediata necesidad militar que impusieron ambas medidas. No he estado en Barcelona pero tengo la impresión de que, en España, las fuerzas de la indisciplina, anarquia, extremismo y jacquerie son extensas, antiguas y fuertes. Y creo que harian imposible la supervivencia del tipo de régimen que Negrín dice concebir para después de la derrota o desplome de los Blancos. La guerra continúa por la misma razón por la que empezó. Y empezó porque un gobierno civil de Frente Popular se desintegró y abrió paso a una extensa jacquerie. Franco y sus amigos no vieron la manera de frenarla y, de hecho, era evidente que no había otra manera excepto con un golpe militar». FO $371 / 24147$ W1415.

${ }^{47}$ Acta del gabinete, 8-11-1939. CAB 23/97. Telegramas del cónsul en Palma (25 y 31-1); informe del comandante del buque "Devonshire» (12-II-1939). FO 371/24146 W1404, W1857 y W6132.

${ }^{48}$ Telegramas de Lord Halifax al encargado de negocios ante la República y al agente en Burgos, 14 y 27-11-1939. FO 425/416.
} 
dición, pese a la simpatia con que fue recibido. De hecho, sectores influyentes del Foreign Office consideraron que la resistencia encontrada por Casado demostraba «que el general Franco ha estado realmente luchando contra el comunismo en España» ${ }^{49}$. Solamente tras la rendición incondicional de fines de marzo, Londres aceptó que la Royal Navy recogiera en Gandía a dos centenares de dirigentes republicanos, entre ellos $\mathrm{Ca}$ sado, y les concedió asilo en Gran Bretaña.

El final de la guerra no eliminó las inquietudes británicas respecto a España. Aún antes de que hubiese terminado, Hitler habia invadido lo que restaba de Checoslovaquia y Franco habia firmado el Pacto Anti-Comintern. Pocos dias después, Mussolini ocupaba Albania. En ese contexto, el Foreign Office reconoció su fracaso en el cumplimiento de uno de los objetivos establecidos como esenciales al comienzo del conflicto: garantizar, como mínimo, la neutralidad estricta de España en caso de guerra europea. En el informe sobre la situación europea elaborado a mediados de abril de 1939, el Foreign Office recomendó a los Jefes de Estado Mayor que planificasen la defensa imperial sobre el supuesto de que España «será neutral, pero interpretará su neutralidad en un sentido fuertemente favorable al Eje» y «pudiera ser que se uniese al enemigo como beligerante ${ }^{50}$. Hasta el comienzo de la guerra mundial, la incertidumbre y el temor continuaron siendo los elementos claves en las apreciaciones británicas sobre la España franquista. Paralelamente, la fe en la diplomacia de la libra para garantizar esa neutralidad hispana fue sustituida por la confianza en el efecto paralizante del cansancio y destrucción provocados por la guerra y del temor a la capacidad anglo-francesa de bloqueo naval y ocupación de la colonia marroqui ${ }^{51}$. Cuando finalmente estalló la guerra europea y la neutralidad franquista se reveló tan malévola como se había previsto, Vansittart redactó el siguiente epitafio sobre la política británica en la guerra civil:

Esta siempre fue la consecuencia inevitable de una victoria de Franco; a su vez, la consecuencia inevitable del cierre de la frontera francesa

49 Minuta de Mounsey al memorándum de Mr. Cowan sobre el final de la guerra civil en Madrid, 19-IV-1939. FO 371/24129 W5827. Sobre los rumores de que Casado actuó con apoyo británico a través de Cowan, comparto la tesis negativa de ALPERT, M., El Ejército republicano en la guerra civil (2. ${ }^{\circ}$ ed., Madrid 1989), págs. 278 y ss.

${ }^{50}$ Informe politico para el Comité de Defensa Imperial, 17-IV-1939. FO 371/23743 R3989.

51 Junta de Jefes de Estado Mayor: Nota sobre el efecto probable del bloqueo de todas las importaciones maritimas de España sobre su potencia y resistencia armada en caso de guerra, 13-V. CAB 53/49. Memorándum de Mr Roberts, 19-V. FO 371/24159 W8087. Informe del comandante Mahony, 26-VI. FO 371/24131 W11396. Acta del gabinete, 26-VIl-1939. CAB $23 / 100$. 
y de toda la farsa partidista de la No Intervención. Yo nunca entendí cómo podía esperarse que dicha política tuviera un resultado distinto del que ahora contemplamos ${ }^{5 ?}$.

En definitiva, antes de que se llegara al Anschluss y a Munich, la guerra civil habia servido como escenario principal de aplicación de la política de apaciguamiento y, a la par, se habia ido convirtiendo en el campo de prueba privilegiado de su viabilidad. La única diferencia con los dos casos citados, pero una diferencia esencial para infortunio de la República española, fue que la prevención antirrevolucionaria siguió operando en los análisis y decisiones de las autoridades británicas hasta la extinción del conflicto. De no contar este factor político-ideológico, resulta incomprensible el grado de pasividad inhibitoria mostrado frente a los riesgos político-estratégicos que fueron surgiendo para la seguridad de un área vital en la defensa del Imperio. Sin duda, el sacrificio de una España «roja» fue juzgado un precio razonable por la codiciada amistad italiana y la ilusión de preservar la paz europea y, en consecuencia, el gobierno británico «tomó agua y se lavó las manos».

${ }^{52}$ Minuta, 20-X-1939. FO 371/23168 C16669. 